\title{
Jan van Kessel II versus Jacques Courtilleau: Dos maneras de retratar a la reina Mariana de Neoburgo
}

\author{
Jan van Kessel II versus Jacques Courtilleau: Two ways of \\ portraying Queen Maria Anna of Neuburg
}

\section{Gloria Martínez Leiva ${ }^{1}$}

InvestigArt

Resumen: Durante la última década del siglo XVII el retrato de corte español se movió entre el naturalismo y la idealización. Orbitó así entre la tradición que se arrastraba desde mediados de la centuria en la representación regia y los nuevos aires que llegaban de Francia. Dos pintores representan como nadie estas dos tendencias dentro de la retratística de la reina Mariana de Neoburgo, el flamenco Jan van Kessel II y el francés Jacques Courtilleau. Con este artículo queremos profundizar en sus modos pictóricos y añadir algunas obras a sus casi desconocidos catálogos.

Palabras clave: Mariana de Neoburgo, Jan van Kessel II, Jacques Courtilleau, Juan Carreño de Miranda, Claudio Coello, retrato palatino, naturalismo, idealización.

\begin{abstract}
During the last decade of the Seventeenth Century the Spanish Court portrait moved between naturalism and idealization. Orbiting between the traditional from the middle of the century, and the new airs coming from France. Concerning the portraits of Queen Maria Anna of Neuburg, two painters represent these tendences like no other: The Flemish master Jan van Kessel II, and the French painter Jacques Courtilleau. Moreover, this paper is intended to delve into both painters' pictorial styles, with the aim of including works to their lesser known œuvre.
\end{abstract}

Key-words: Maria Anna of Neuburg, Jan van Kessel II, Jacques Courtilleau, Juan Carreño de Miranda, Claudio Coello, Palatine Portrait, naturalism, idealization.

\footnotetext{
I (ㄷ) http://orcid.org/0000-0002-7388-3989
}

(C) 2019 Philostrato. Revista de Historia y Arte 


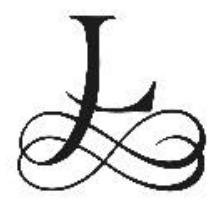

os diversos retratos que se realizaron de la reina Mariana de Neoburgo (1667-1740) durante los diez años que estuvo casada con el monarca español Carlos II permiten ver claramente la evolución de la moda y de los gustos de la Corte durante esa década. Asimismo, dejan a las claras el cambio del paradigma artístico y estético que tendrá lugar en ese tiempo, pasando del más austero hispánico al ampuloso francés. Dos pintores al servicio de la reina muestran a la perfección las dos corrientes que en el retrato se darán, por un lado, el flamenco Jan van Kessel II (Amberes, 1654-Madrid, 1711), que seguirá la formula marcada por la tradición hispánica $y$, por otro, el francés Jacques Courtilleau (doc. 1696-Bayona, 1713), que introducirá la triunfante corriente gala. Nuestro objetivo con este texto es dar a conocer algunas de las efigies de la soberana ejecutadas por ambos que, pese a carecer de firma o documentación concreta, hemos podido adjudicar gracias a una laboriosa investigación y recolección de retratos durante años ${ }^{2}$.

\section{Van Kessel II, el continuador de la tradición hispánica en el retrato regio}

A la llegada de la reina a Madrid en 1690, el retrato de corte español seguía dominado por la simplicidad de formas y colorido que había impuesto Diego Rodríguez de Silva y Velázquez a mediados de siglo. Sus efigies directas, sin apenas aparato y simbología, y remarcando la figura de la representada sobre un fondo neutro, servirán de modelo a Juan Carreño de Miranda y a los pintores de la primera mujer de Carlos II, María Luisa de Orleans, para configurar su imagen. Crearán así un retrato interesado en la apariencia real de la representada y sin apenas presencia de elementos simbólicos, en especial en lo que a los retratos de busto se refiere ${ }^{3}$. Este tipo de retrato directo será la línea que continúe el pintor de Cámara del rey, Claudio Coello, quien será el encargado de plasmar a Mariana de Neoburgo nada más llegar a la Corte (Fig. 1). Probablemente el retrato que en la actualidad se encuentra en la Fundación Casa Medina Sidonia es esa primera efigie de la reina realizada por Coello a la que Palomino hace referencia en sus Vidas ${ }^{4}$. En el lienzo la reina aparece de tres cuartos, medio perfil y mirando directamente

\footnotetext{
2 Dicha investigación es fruto de una tesis doctoral recientemente defendida en la Universidad Complutense de Madrid, Gloria Martínez Leiva, Mariana de Neoburgo (1667-1740). Escenarios, imagen y posesiones de una reina, Tesis doctoral inédita, Universidad Complutense. (Madrid: 2019).

${ }^{3}$ Sirva como ejemplo de este tipo de efigies la realizada por Juan Carreño de Miranda a María Luisa de Orleans que se conserva en la Colección Banco Sabadell en Oviedo (óleo sobre lienzo, $63 \times 60 \mathrm{~cm}$ ). Gloria Martínez Leiva, "El exilio de la reina viuda Mariana de Neoburgo y la configuración de un nuevo retrato áulico", en Carlos II y el Arte de su Tiempo, coords. Alfonso Rodríguez G. de Ceballos y Ángel Rodríguez Rebollo, (Madrid: Fundación Universitaria Española, 2013), p. 241, Fig. 1.

4 "Y habiéndose celebrado el segundo matrimonio del Señor Carlos Segundo en el año de 1690, retrató también Claudio [Coello] à la Reina nuestra Señora Doña María Ana de Neoburg". Antonio Palomino de
} 


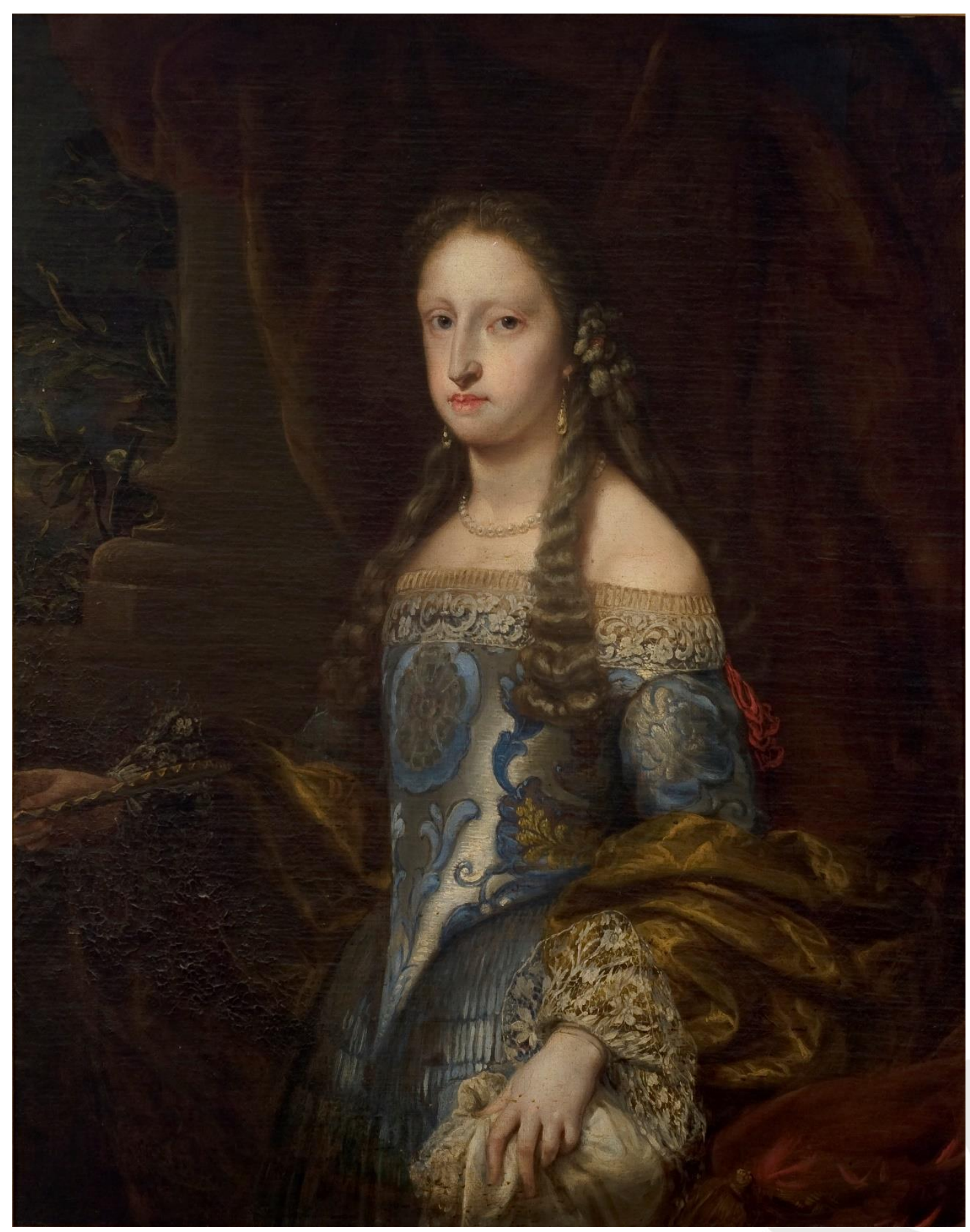

Fig. 1. Claudio Coello, Mariana de Neoburgo, 1690, (Óleo sobre lienzo, 106 x 86 cm). Sanlúcar de Barrameda, Fundación Casa Medina Sidonia. @ F Fundación Casa Medina Sidonia

al espectador. Luce vestida a la española y en su mano derecha lleva un abanico abierto de perfil, en un alarde en el manejo de la perspectiva, mientras que con su mano izquierda sujeta un pañuelo de lienzo blanco y

Castro, El Museo pictórico y escala óptica. II. Práctica de la Pintura y III. El Parnaso español pintoresco y laureado, (Madrid: Ed. Aguilar, 1947), p. 1064. 
encaje. Aunque su figura destaca sobre el fondo, éste ya no es neutro, dado que Coello introdujo en la obra el paisaje y la luz natural, elementos que permitirán la prolongación del sencillo modelo hispánico durante unos años más. Este primer retrato de la soberana gozará de gran éxito y servirá de guía a los pintores de la reina para difundir su imagen tanto dentro como fuera de la Corte. Prueba de ello es el hecho de que se hayan encontrado al menos seis efigies que siguen con bastante fidelidad el modelo plasmado por Coello 5 .

Entre los artistas que copiarán la imagen realizada por Coello estará Jan van Kessel II (Fig. 2), quien por su maestría a la hora de realizar retratos será comparado con Van Dyck ${ }^{6}$, y que ocupará plaza de pintor honorario de la reina desde el 29 de noviembre de $1683^{7}$. Este lienzo sigue prácticamente el realizado por Coello y por su estilo pictórico y semejanza a la hora de realizar el rostro y los cabellos con el de la colección Abelló hemos podido atribuirlo a Jan van Kessel II $^{8}$. Van Kessel II era un pintor de origen flamenco, cuyo padre, el también artista Jan van Kessel el Viejo (1626-1679), fue un conocido pintor de bodegones, género que marcará especialmente a su hijo, que será iniciado por él en el oficio de los pinceles. Durante el tiempo que Van Kessel el Joven sirvió a María Luisa de Orleans pintó numerosos retratos de ella y también decoró parte de la Galería del Cierzo del Alcázar ${ }^{9}$. El 10 de abril de 1697 Van Kessel todavía reclamaba dinero por "quantto de diez y nueve rettrattos que hizo para servizio de su Magestad la Reina nuestra señora Doña Maria Luisa de Borbon, asi de su Real Persona, como ottros que se le quedaron deviendo a el ottorgantte diferentes cantidades de maravedis..."10. Una vez llegada Mariana de Neoburgo, su principal función será la de retratar a la soberana durante los años que la sirvió, los cuales se extendieron incluso durante su exilio toledano.

La única obra que a ciencia cierta pintó Van Kessel II de la reina es el retrato que, junto al de su esposo, realizó para el duque del Infantado, de cuyo pago hay constancia en 7 de octubre de 1693, y que hoy se encuentra en la colección Abelló (Fig. 3) ${ }^{11}$. No obstante, por la proximidad estilística a

\footnotetext{
${ }^{5}$ Martínez Leiva, Mariana de Neoburgo, vol. II, pp. 54-63, cats. IM13/1-IM13/6.

${ }^{6}$ Así lo consideró Gregorio Mayans y Siscar en su Arte de Pintar en 1776. Matías Díaz Padrón, "Prestigio y fortuna crítica de Van Dyck en los tratadistas españoles", Archivo Español de Arte, 333, (2011), p. 54.

7 Archivo General de Palacio (AGP), Personal, Ca 1314/19, s.f.; Ángel Aterido, El final del Siglo de Oro. La pintura en Madrid en el cambio dinástico (1685-1726), (Madrid: CSIC, 2015), vol. II, p. 166.

8 Martínez Leiva, Mariana de Neoburgo, vol. II, pp. 54-55, cat. IM13/1. No obstante, es de notar que la obra resulta más oscura de lo habitual en Van Kessel II. Esto puede deberse, como una reciente intervención en la pintura ha demostrado, a que se encuentra bastante barrida y por lo tanto en muchos puntos es visible el color rojizo de la preparación de la pintura, lo que hace que su percepción se vea desvirtuada.

${ }^{9}$ Sobre las decoraciones de la Galería del Cierzo de la reina véanse Palomino, El Museo pictórico, p. 1089; Edward J. Sullivan, Claudio Coello y la pintura barroca madrileña, (Madrid: Nerea, 1989), p. 84; José Manuel Barbeito, El Alcázar de Madrid, (Madrid: Colegio Oficial de Arquitectos de Madrid, 1992), pp. 194195, y Ángel Rodríguez Rebollo, "A propósito de Luca Giordano: Los Reales Sitios durante el reinado de Carlos II. Una aproximación a través de los inventarios", en Carlos II y el Arte de su Tiempo, coords. Alfonso Rodríguez G. de Ceballos y Ángel Rodríguez Rebollo, (Madrid: Fundación Universitaria Española, 2013), pp. 117-118.

${ }_{10}$ AGP, Personal, Ca 1314/19, s.f.

${ }_{11}$ Aterido, El final del Siglo de Oro, vol. II, p. 167; Martínez Leiva, Mariana de Neoburgo, vol. II, pp. 8992, cat. IM21.
} 


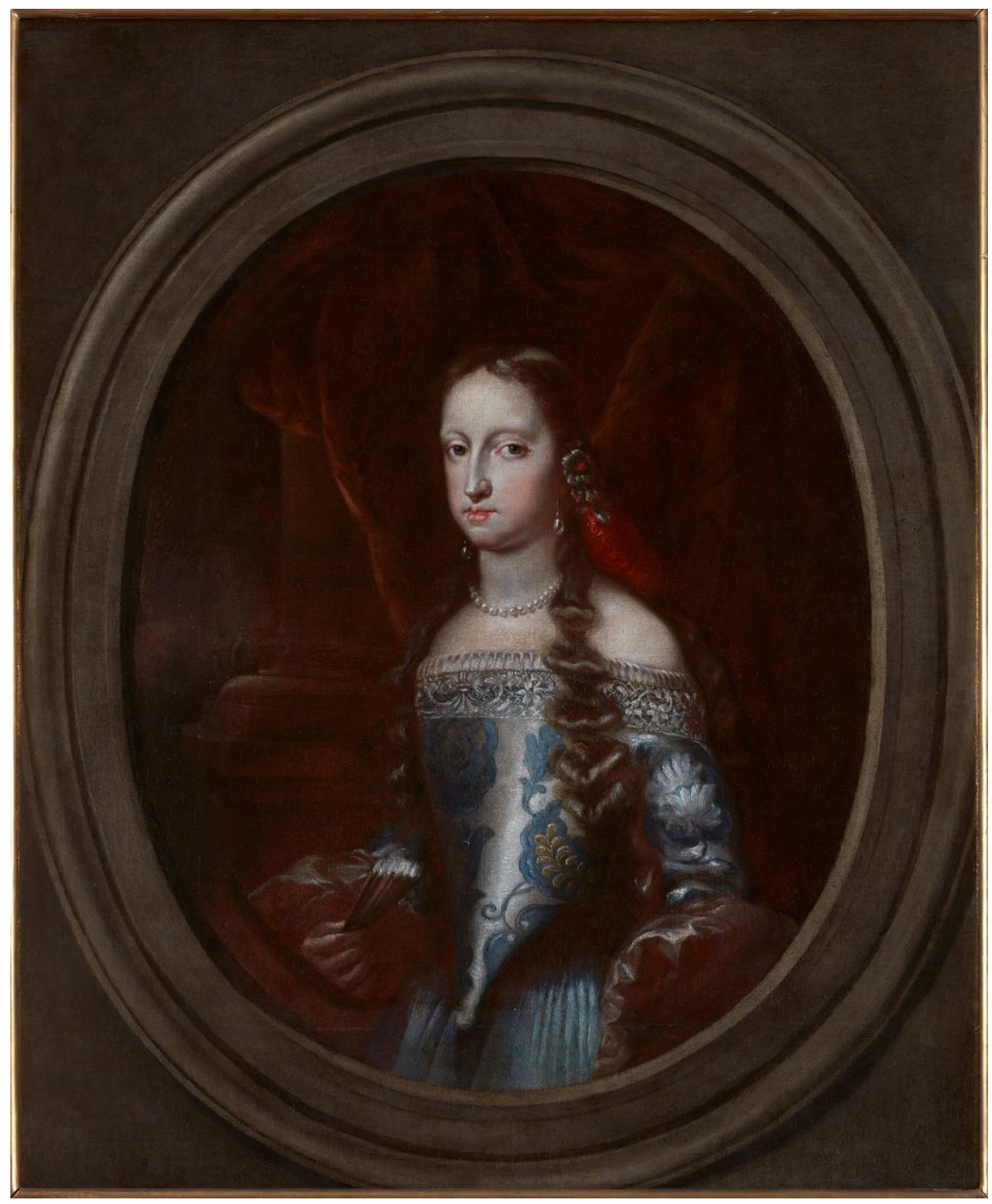

Fig. 2. Jan van Kessel II (atribuido), Mariana de Neoburgo, 1690, (Óleo sobre lienzo, 120 x 100 cm). Madrid, Colección particular. @ F Fotografía: Joaquín Cortés

éste, se le han podido atribuir seis obras más, desde el que acabamos de citar copiando a Coello a los que analizaremos a continuación. Sin embargo, todavía es muy probable que surjan más pinturas de su mano ya que, por ejemplo, sabemos que el Museo Nacional del Prado poseía un retrato de "Da Mariana de Neubourg segunda esposa de Carlos II en pié de Tamaño Natural original de Wantressel", que fue donado por Vicente y Mariano Carderera al museo el 5 de julio de $1880^{12}$. El retrato fue seleccionado entre las dieciséis pinturas que fueron cedidas en depósito a la Diputación provincial de Santiago de Cuba en $1893^{13}$ y se encuentra en paradero desconocido desde $1902^{14}$.

12 Museo del Prado. Inventario General de Pinturas. III Nuevas Adquisiciones, Museo Iconográfico y Tapices, (Madrid: Museo del Prado, 1996), p. 140, no 509.

13 Archivo del Museo Nacional del Prado (AMNP), Ca 90, leg. 15.19, exp. 18_1.

14 Martha Elizabeth Laguna Enrique, El Museo Nacional de Bellas Artes de la Habana y la colección de retratos de pintura española del siglo XIX, (Salamanca: Universidad de Salamanca, 2013), pp. 420-421. 


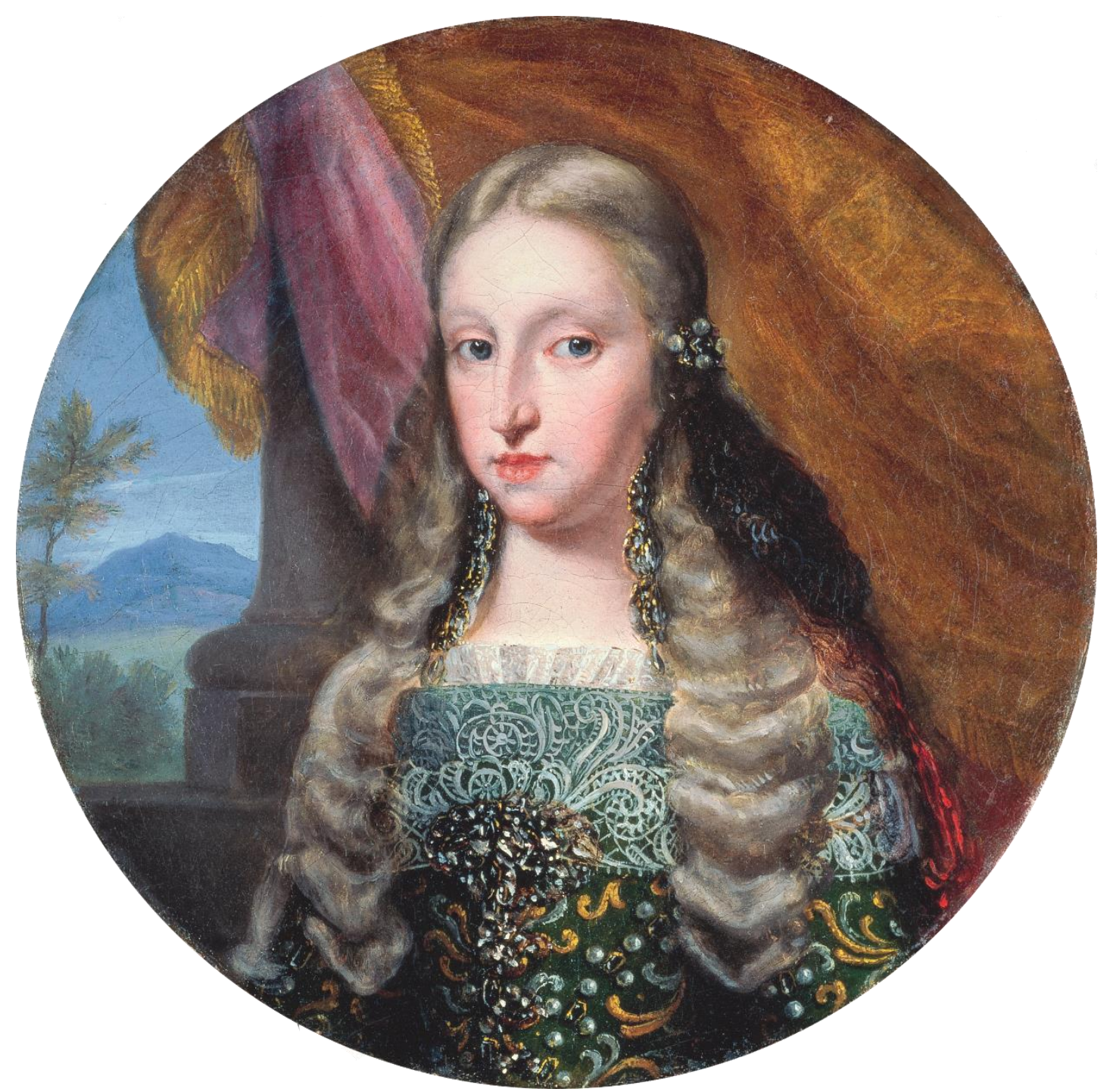

Fig. 3. Jan van Kessel II, Mariana de Neoburgo, 1690-1693, (Óleo sobre lienzo, 29,5 cm Ø). Madrid, Colección Abelló. (C) Fotografía: Joaquín Cortés

El retrato de busto realizado por Van Kessel II para el duque del Infantado sigue una fórmula cercana a la efigie creada por Claudio Coello ${ }^{15}$. En él la reina aparece reflejada en un escenario que ya no es neutro, sino que tras ella se entreabre un cortinaje que deja ver un paisaje y un trozo de columna. La luz más clara, contrastando menos las luces y sombras, y el colorido más vivo e intenso, unido al paisaje, comenzarán a llevar al retrato regio hacia un nuevo horizonte. De hecho, en algunos retratos para la nobleza Van Kessel había comenzado ya a experimentar con la apertura total hacia el paisaje exterior, como es el retrato que aquí atribuimos por primera vez al artista y creemos que podría representar a María Nicolasa de la Cerda (Fig. 4), hija

15 María Teresa Zapata, La entrada en la Corte de María Luisa de Orleans. Arte y fiesta en el Madrid de Carlos II, (Madrid: Fundación de Apoyo a la Historia del Arte Hispánico, 2000), pp. 199-200, fig. 179; Álvaro Pascual Chenel, El retrato de Estado durante el reinado de Carlos II. Imagen y propaganda, (Madrid: Fundación Universitaria Española, 2010), p. 588, cat. MN5; Martínez Leiva, "El exilio de la reina viuda...", p. 221, Fig. 4. 
pequeña del VIII duque de Medinaceli, valido de Carlos II, nacida en 1680. El destacado lugar que en la corte ocupaba Juan Francisco de la Cerda le permitió estar en contacto con los pintores al servicio de los soberanos, de hecho se conserva un retrato de él realizado por Claudio Coello ${ }^{16}$. Dada la edad de la representada, unos cinco años, y las similitudes del jardín con el de la residencia que el duque de Medinaceli poseía en el Paseo del Prado, con fuentes y una alta tapia con nichos y esculturas ${ }^{17}$, creemos que podría tratarse de la hija pequeña del duque y que pudo ser realizado hacia 1685 . Este retrato consta en la actualidad en el inventario del Museo del Prado como retrato anónimo de Niña cogiendo un lirio. La dulzura del rostro, el colorido vivo, el contraste entre una luz clara y sombras cuidadosamente empleadas, la realización de tejidos y bordados, etc. poseen la misma calidad y características que se observan tanto en la efigie de Mariana de Neoburgo de la colección Abelló como en el retrato de Familia en un jardín, cuadro éste fechado y firmado por Van Kessel II en 1679 (Fig. 5) ${ }^{18}$. Asimismo, las fuentes y esculturas de este último lienzo son muy similares y presentan la misma técnica que las que podemos observar en el retrato de la niña ${ }^{19}$.

El retrato en tondo de Van Kessel II de la colección Abelló, que tiene como pareja otro del rey Carlos II, resulta muy interesante ya que, gracias a las investigaciones realizadas por el profesor Aterido, se ha podido saber que ambos fueron en su origen concebidos como lienzos rectangulares, en los que se representaba una guirnalda de flores en cuyo centro estaba la efigie de los monarcas $^{20}$. En algún momento entre mediados de los siglos XVIII y XIX se cercenaron separando el retrato de la guirnalda y es por ello que los tondos presentan un aspecto irregular y deshilachado. La tipología de las guirnaldas con escenas en su interior contenía con mayor frecuencia iconografías religiosas o alegóricas como, por ejemplo, la Guirnalda con el Niño Jesús y san Juan que se conserva en el Prado ${ }^{21}$. El cobre está firmado en la parte inferior "J.V. Kessel. Fecit", y aunque en las colecciones del museo está atribuida a Jan van Kessel el Viejo tanto la pincelada, como el colorido, con

\footnotetext{
16 Museu Nacional D'Art de Catalunya, óleo sobre lienzo, 81,5 x 60,5 cm. (no inv. 064995-000).

17 Resulta curioso que Van Kessel el Joven tenga también atribuida a sus pinceles hacia esas mismas fechas (1686) una vista de la Carrera de San Jerónimo y el Paseo del Prado en la que se puede observar exteriormente la residencia del duque. Museo Thyssen-Bornemisza, óleo sobre lienzo, $164 \times 445 \mathrm{~cm}$. ( $\mathrm{n}^{\circ}$ inv. CTB.19998.81). (En web: https://www.museothyssen.org/en/collection/artists/kessel-iii-jan-vanattributed/view-carrera-san-jeronimo-and-paseo-prado, consultada: 22 de septiembre de 2019).

${ }^{18}$ La calidad de esta obra le llevó a afirmar a Palomino que si no hubiera sido por la firma "sería reputado por obra de Van Dyck". Matías Díaz Padrón, "Van Dyck: La influencia del retrato del más prestigioso discípulo de Rubens en la pintura española del siglo XVII", Anuario de Estudios Atlánticos, 54-II, (2008), p. 246.

19 También el escenario guarda semejanza con el Retrato de familia, atribuido con acierto por el profesor Enrique Valdivieso a Jan van Kessel el Joven, que salió a la luz en 1983. Enrique Valdivieso González, "Un nuevo retrato de familia de Jan Van Kessel, el Joven", Boletín del Seminario de Estudios de Arte y Arqueología, 49, (1983), pp. 492-493. (En web:

https://rkd.nl/nl/explore/images/record?filters\%5Bkunstenaar\%5D=Kessel\%2C+Jan+van+\%28II\%29\& query $=\&$ start $=13$, consultada: 20 de octubre de 2019).

${ }^{20}$ Aterido, El final del Siglo de Oro, vol. I, p. 82.

${ }^{21}$ Museo Nacional del Prado (MNP), óleo sobre cobre, $101 \times 80 \mathrm{~cm}$. (nº cat. P001552).
} 


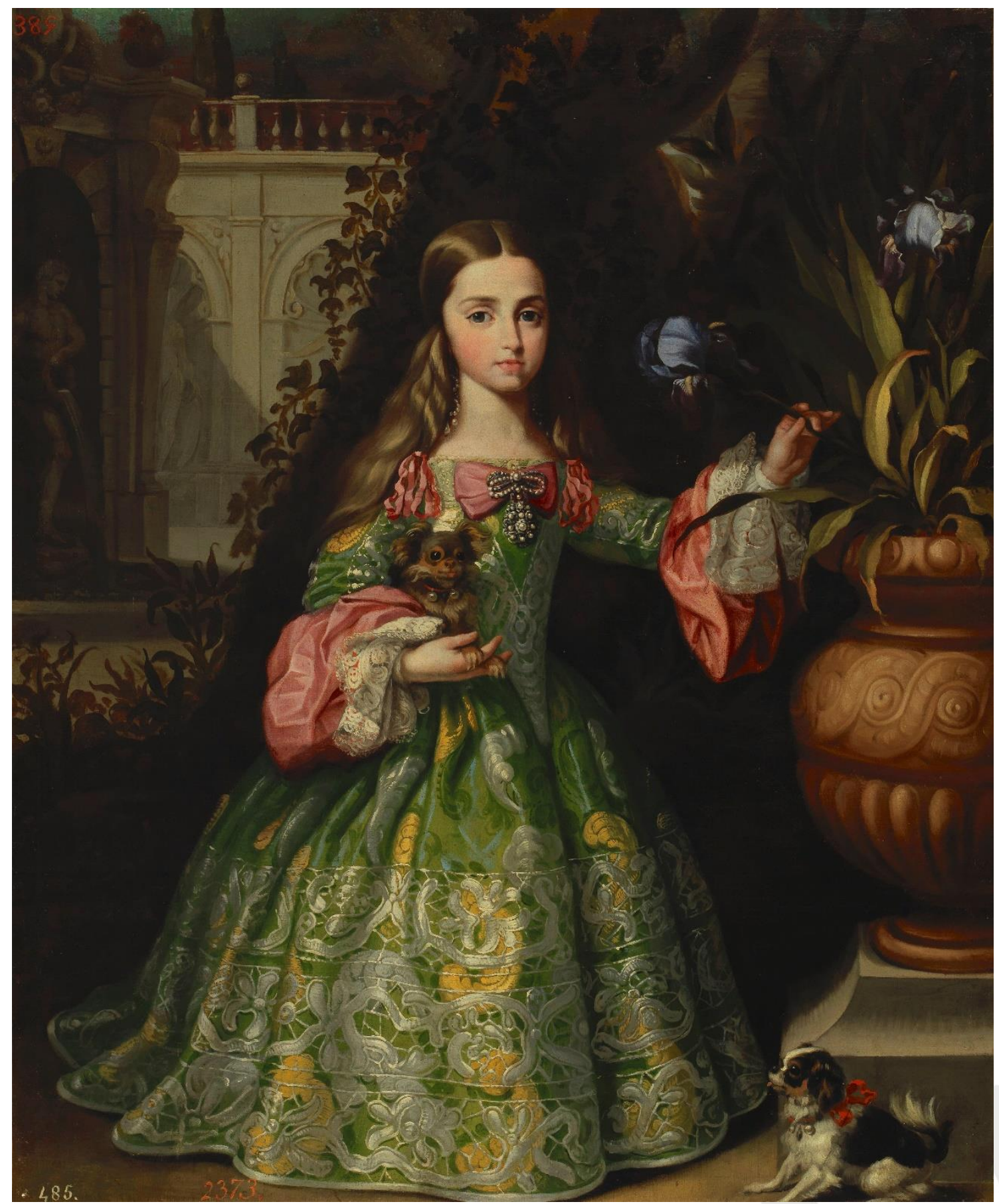

Fig. 4. Jan van Kessel II (atribuido), Posible retrato de María Nicolasa de la Cerda, hija pequeña del VIII duque de Medinaceli, ca. 1685, (Óleo sobre lienzo, 120 x 100 cm). Madrid, Ministerio de Administración Pública, en depósito del Museo Nacional del Prado ( $\mathrm{n}^{\circ}$ cat. P006347). (C) Museo Nacional del Prado

un mayor uso de los contrastes lumínicos, encajan mejor dentro de la producción de Van Kessel II, quien también representó con maestría las diversas especies botánicas. En el cobre el espacio dedicado a la escena religiosa tiene forma circular y sus dimensiones rondan los treinta centímetros de circunferencia, características muy similares al tondo Abelló. Esto nos ha permitido reconstruir cómo podría haber sido el aspecto del lienzo 


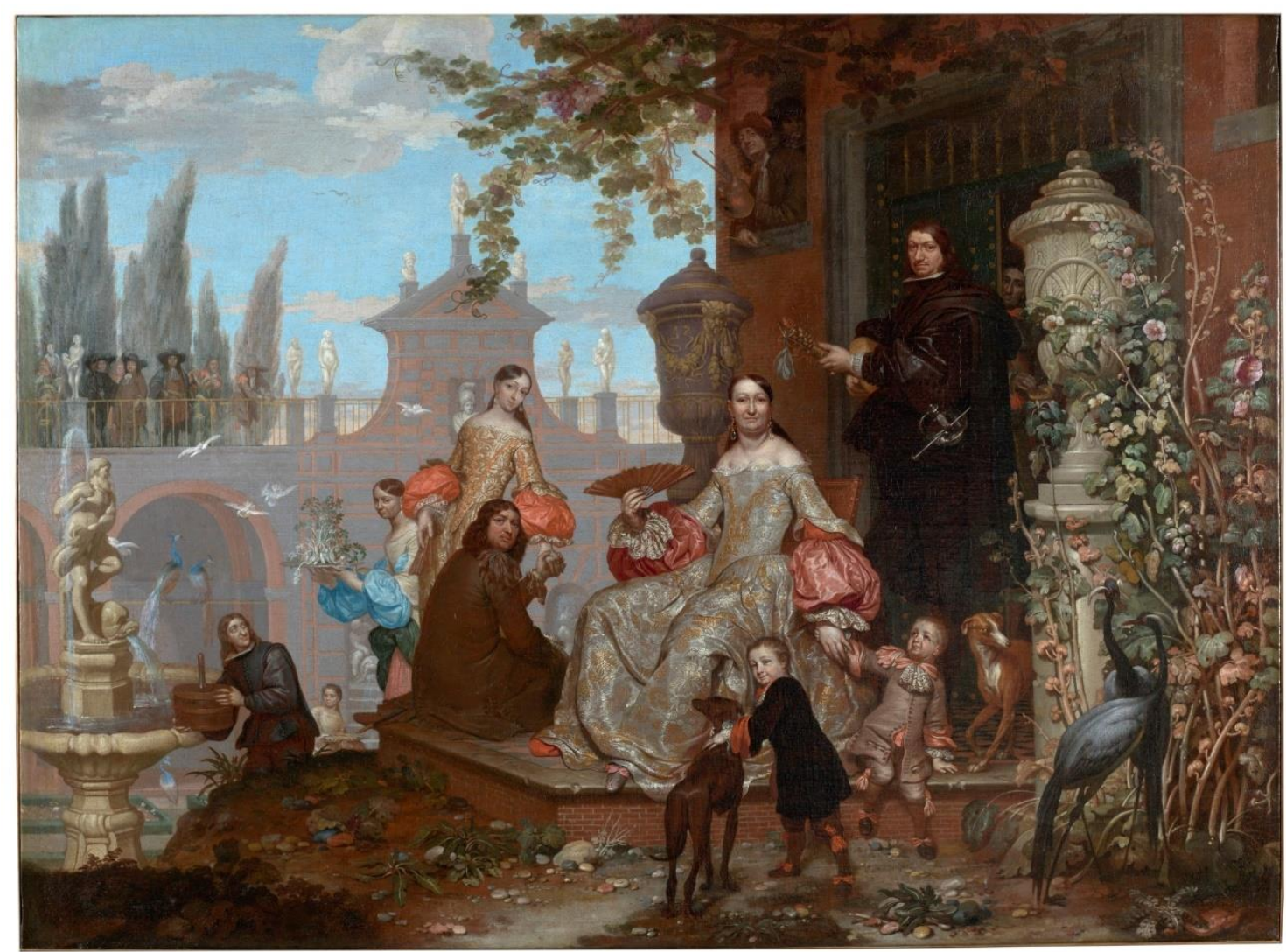

Fig. 5. Jan van Kessel II, Familia en un jardín, 1679, (Óleo sobre lienzo, 127 x 167 cm). Madrid, Museo Nacional del Prado ( $\mathrm{n}^{\circ}$ cat. P002525). () Museo Nacional del Prado

pintado originalmente por Van Kessel el Joven antes de que los retratos fueran separados de la guirnalda (Fig. 6). Se conservan algunos ejemplos de obras en los que las guirnaldas se utilizaron en el género del retrato, consiguiendo así sacralizar esas imágenes y permitiendo a través de flores y frutos añadir elementos iconográficos que aportaban significación. Es el caso del Retrato del rey Christian $V$ de Dinamarca realizado por Jan Pauwel Gillemans el Joven (1651-1704), artista flamenco especializado en naturalezas muertas, con el soberano en el centro de la composición representado de busto en el interior de una ojiva y rodeado de una guirnalda de flores y frutos ${ }^{22}$. Los retratos ejecutados por Jan van Kessel II estaban pues en consonancia con otros realizados en Europa en las postrimerías del siglo XVII.

Finalmente, respecto a este retrato de Van Kessel II de la colección Abelló queremos hacer una última consideración. A través de la fotografía antigua que de la obra se conserva en el Instituto del Patrimonio Histórico Español ${ }^{23}$,

\footnotetext{
22 Hillerod (Dinamarca), The National Museum of History Frederiksborg Castle ( $n^{\circ}$ inv. R192).

${ }^{23}$ Casa Moreno, Archivo de Arte Español, no inv. 01627_B. (En web:

http://www.mcu.es/fototeca_patrimonio/Visor?usarVisorMCU=true\&archivo=MORENO/preview/01627_B _P.jpg, consultada: 20 de octubre de 2019).
} 


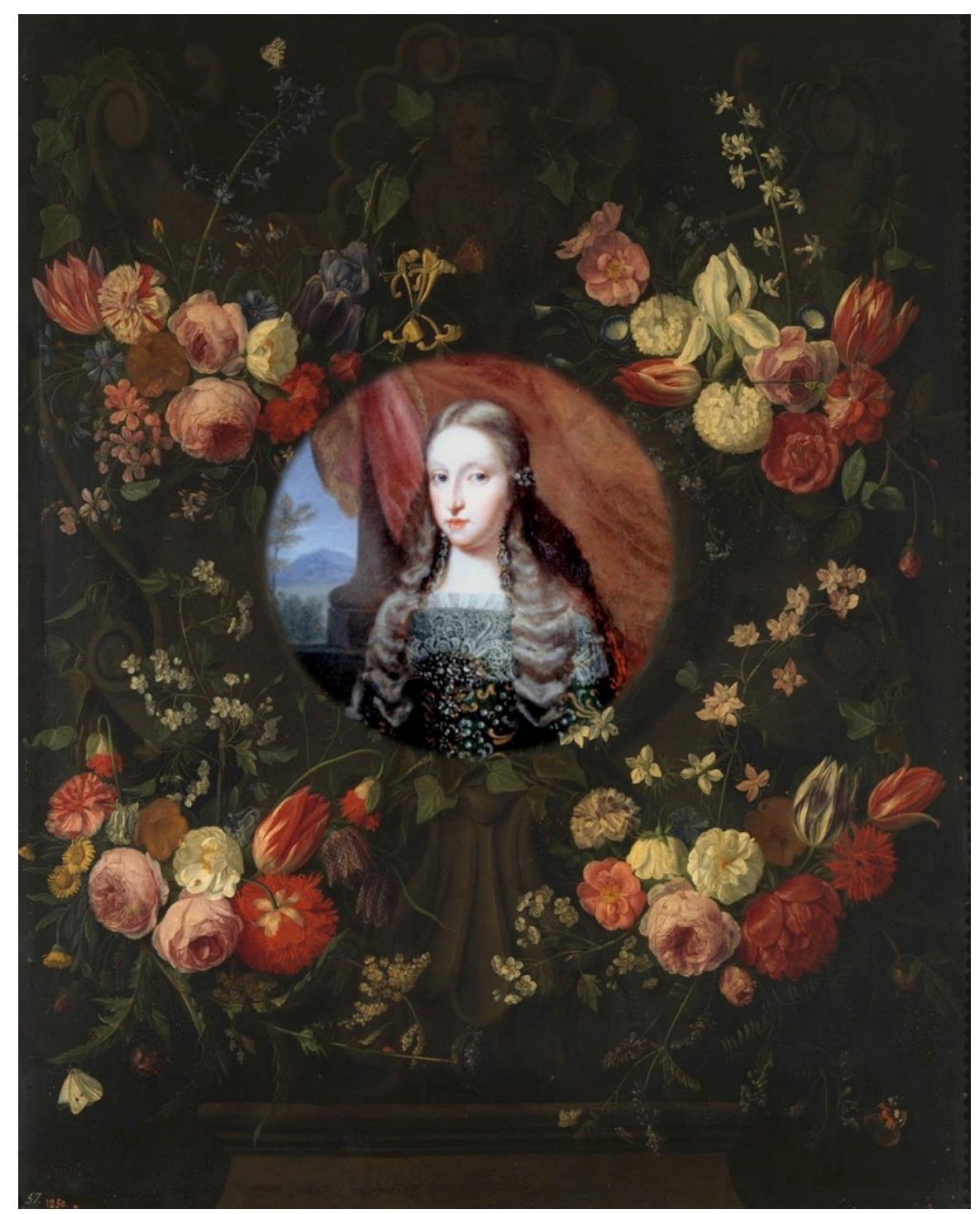

Fig. 6. Reconstrucción del hipotético aspecto del retrato de la reina Mariana de Neoburgo por Jan van Kessel II. () Fotomontaje de la autora (Imágenes utilizadas: Jan van Kessel II, Guirnalda con el Niño Jesús y san Juan, finales del siglo XVII, (Óleo sobre cobre, 101 x $80 \mathrm{~cm}$ ). Madrid, Museo Nacional del Prado (nº cat. P001552); y Jan van Kessel II, Mariana de Neoburgo, 1690-1693, Madrid, Colección Abelló. (Fig. 1)

se puede apreciar cómo el peinado de la reina había sufrido un retoque, presentando un tupé en la parte delantera del cabello, para acomodarlo a la moda de hacia 1692-1693 y así actualizar la imagen de la soberana antes de la entrega de las pinturas al duque del Infantado en $1693^{24}$. Este repinte, seguramente realizado por el propio artista flamenco, fue levantado con una restauración posterior de la obra, posiblemente al ser adquirido por la colección Abelló, desvirtuando así el aspecto y cronología de la obra.

${ }^{24}$ El 7 de octubre de 1693 se pagaron 1.200 reales a Jan van Kessel "en que se ajustaron dos Retratos que hizo de orden de su exa". Aterido, El final del Siglo de Oro, vol. I, p. 170, nota 256. 
La imagen del tondo Abelló, todavía sin haberse levantado el repinte del cabello, es prácticamente idéntica a la de otro retrato de la reina que puede ser atribuido a Van Kessel II con bastante certeza ${ }^{25}$. Se trata de una efigie en busto de la soberana que se conserva en una colección particular madrileña. La obra, de una inmensa calidad, muestra exactamente la misma técnica a la hora de realizar los caireles del pelo y el rostro de la soberana. Asimismo, el paisaje del fondo es idéntico en ambos lienzos, pero en este caso con una luz crepuscular de atardecer en vez de clara de día como en el tondo ${ }^{26}$.

Otro de los primeros retratos que se debió de realizar de Mariana poco después de su llegada a Madrid fue el de la "Quadra del Mediodía" en El Escorial (Fig. 7) 27. En 1681 Juan Carreño de Miranda había pintado para ese espacio un retrato de Carlos II y otro de María Luisa de Orleans, para reemplazar sendas efigies realizadas por Juan Bautista Martínez del Mazo de Carlos II niño y Mariana de Austria. Carlos II fue retratado por Carreño con armadura ${ }^{28}$, siguiendo el mismo modelo que el propio pintor había realizado para ser llevado a Francia con motivo de las negociaciones de la boda con María Luisa de Orleans en 1679. Por su parte, el de María Luisa de Orleans, que se consideraba réplica de la obra del Monasterio de Guadalupe en Cáceres $^{29}$, se sustituyó tras su muerte por uno de Mariana de Neoburgo, que no es otro que del que aquí tratamos. En éste la reina aparece representada de cuerpo entero con un traje de seda azul bordado en oro y plata, luciendo en el pecho un gran joyel en forma de lazo. Su larga melena está peinada con raya al medio y dos caireles trenzados descansan sobre sus hombros. El escenario en el que se sitúa es una sala con suelos ajedrezados en blanco y tierra. A su derecha se vislumbra uno de los bufetes con pies de leones de bronce del Salón de los Espejos del Alcázar de Madrid. Sin embargo, el paisaje que se deja entrever por el lado izquierdo de la composición, al igual que ocurre con el navío luchando en el mar que puede observarse en el retrato de su esposo, no corresponde con esa ubicación. Así pues, se usó el bufete como elemento simbólico de la monarquía y de la Casa de Austria, objeto de los más representativos en la configuración del retrato regio que ya había utilizado Carreño, pero el escenario es una fabulación.

El retrato de Mariana para la "Quadra" está atribuido a Claudio Coello, considerándose como la configuración por parte de éste de un nuevo prototipo oficial para representar a la soberana. Sin embargo, tres son los

\footnotetext{
${ }^{25}$ Madrid, Colección particular, óleo sobre lienzo, 83 x $65 \mathrm{~cm}$. (En web:

http://www.mcu.es/fototeca_patrimonio/Visor?usarVisorMCU =true\&archivo=INFORMACION\%20ARTISTI CA\%20-\%20JUNTA\%20TESORO/preview/AJP-0587_P.jpg, consultada: 20 de octubre de 2019).

${ }^{26}$ Martínez Leiva, Mariana de Neoburgo, vol. II, pp. 96-99, cat. IM23.

27 Para lo relativo a las decoraciones de la Quadra del Mediodía y al cuadro de Mariana en concreto: Carmen García-Frías, "La retratística de la Casa de Austria en el Monasterio del Escorial", en El Monasterio del Escorial y la pintura, (San Lorenzo de El Escorial: Real Centro Universitario Escorial-María Cristina, 2001), pp. 418-419; Carmen García-Frías, "Dos dibujos inéditos de los Aposentos Reales de San Lorenzo de 1755", Reales Sitios, 150, (2001), pp. 16-25; Pascual Chenel, El retrato de Estado, pp. 105, 582-583, cat. MN2; Martínez Leiva, "El exilio de la reina viuda...", p. 223; El retrato en las colecciones reales de Patrimonio Nacional. De Juan de Flandes a Antonio López, (Madrid: Patrimonio Nacional, 2014), pp. 250253, cat. 42; y Martínez Leiva, Mariana de Neoburgo, vol. II, pp. 64-70, cat. IM14.

${ }_{28}$ MNP, óleo sobre lienzo, $232 \times 125,5 \mathrm{~cm}$. (n० cat. P007101).

29 Real Monasterio de Guadalupe, óleo sobre lienzo, $210 \times 147 \mathrm{~cm}$.
} 
motivos por los que lo consideramos obra de Van Kessel II. El primero de ellos es la existencia de un lienzo que muestra a María Luisa de Orleans con la misma iconografía ${ }^{30}$. Este óleo, posiblemente copia de Francisco Ignacio Ruiz de la Iglesia del cuadro que Carreño pintó para El Escorial, indicaría que no se creó ningún prototipo nuevo para representar a Mariana de Neoburgo. Probablemente se consideró inadecuado romper el perfecto pendant que los lienzos de ambos soberanos debían conformar, abiertos los dos por un extremo a un paisaje y apoyándose cada uno en uno de los bufetes del Salón de los Espejos, y que por ello lo más conveniente era copiar el modelo ya existente, cambiando tan sólo el rostro de la soberana. Semejante labor de "copia" parece muy por debajo de la cualificación de Claudio Coello, encargado de configurar los modelos que otros pintores debían seguir. Un segundo motivo lo encontramos en el inventario a la muerte de Carlos II donde esta obra se atribuye a "Un Pinttor Moderno" y no a Coello ${ }^{31}$, artista sobradamente conocido en el monasterio y que debería haber sido identificado por el encargado de la relación testamentaria, ya que estuvo durante largo tiempo pintando en el lugar La Sagrada Forma de Gorkum. Por último, aunque el lienzo tiene una gran calidad, muestra un colorido más apagado de lo habitual en Coello, sobre todo en lo que a los tonos azules se refiere; un rostro más plano y una carnalidad y profundidad psicológica menor que el retrato de Medina Sidonia, obra ésta indudable del artista madrileño. Por todo ello consideramos que el lienzo para la "Quadra" del Escorial debe ser atribuido a Jan van Kessel II, cuya calidad pictórica se asemeja más a lo plasmado en este óleo.

Tras la muerte de Coello en 1693, durante un tiempo el retratista principal que quedará al cargo de la representación de la reina será Jan van Kessel el Joven. Éste no sólo realizará lienzos sino también retratos en miniatura de los soberanos ${ }^{32}$, como las exquisitas obras a lo divino en las que la soberana aparece representada como santa Elena (véase Fig. 14), y el rey se muestra como san Fernando 33 . Los soberanos aparecen "travestidos" como dos de los santos más importantes de la cristiandad, dándose además el hecho de que

\footnotetext{
30 MNP, óleo sobre lienzo, $210 \times 123 \mathrm{~cm}$. (nº cat. P007190). Martínez Leiva, "El exilio de la reina viuda...", p. 223, Fig. 8; Martínez Leiva, Mariana de Neoburgo, vol. II, p. 66.

31 "Yttem Ottros dos Rettrattos de el señor Rey Don Carlos Segundo y el Otro de su Señoria Ulttima Sposa del mismo tamaño el de Su Magesttad de mano de Carreño y el de la Reyna nuestra Señora de Un Pinttor Moderno el de Su Magesttad tasado en mill ducados y el Ottro en quinienttos ducados... 16.500". Gloria Fernández Bayton, Inventarios Reales. Testamentaría de Carlos II, (Madrid: Museo del Prado, 1985), vol. III, p. 93, no 18.

32 Del trabajo como miniaturista de Van Kessel II ya teníamos noticia ya que fue el encargado de realizar los retratos de Carlos II que se pusieron en las joyas encargadas tanto por Mariana de Austria como por el rey para regalar a Mariana de Neoburgo con motivo de su enlace. Juan Ramón Sánchez del Peral, "Jan van Kessel II y la Joya Grande de Mariana de Neoburgo: consideraciones sobre el retrato portátil en la época de Carlos II", Reales Sitios, 150, (2001), pp. 65-74.

${ }^{33}$ Las miniaturas pertenecieron a la Galería Caylus y en la actualidad se encuentran en una Colección particular, óleo sobre cobre, $79 \times 65 \mathrm{~mm}$ c/u. Agradecemos a Caylus la información y las imágenes para este texto. Véanse José Luis Sancho y Gloria Martínez Leiva, "¿Dónde está el rey? El ritmo estacional de la corte española y la decoración de los Reales Sitios (1650-1700)", en Cortes del Barroco, de Bernini y Velázquez a Luca Giordano, (Madrid: Patrimonio Nacional, 2003), p. 94, Fig. 66; Pascual Chenel, El retrato de Estado, p. 135, Fig. 79; Martínez Leiva, "El exilio de la reina viuda...", p. 225, Fig. 9; Martínez Leiva, Mariana de Neoburgo, vol. II, pp. 181-183, cat. IMR3.
} 


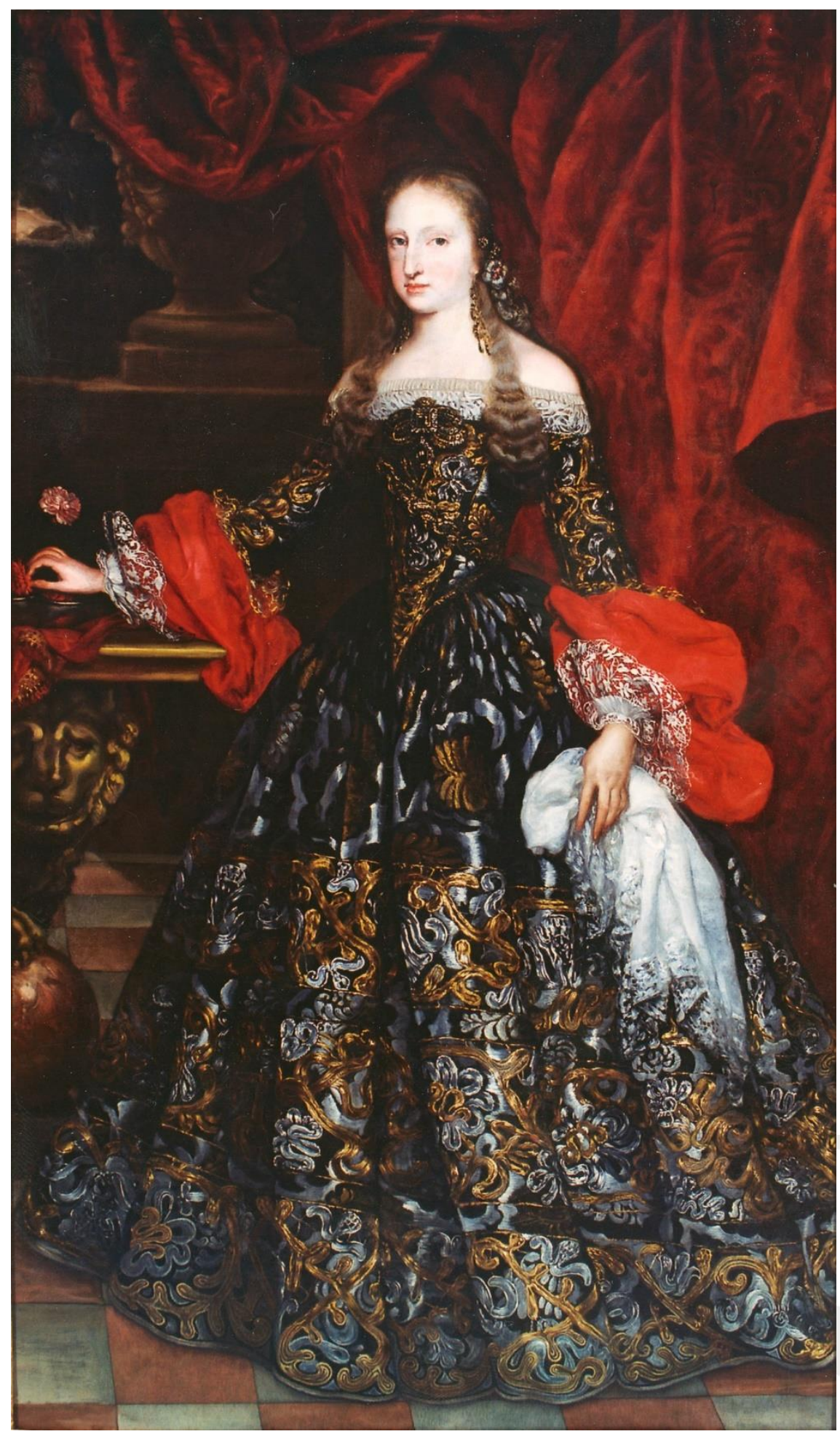

Fig. 7. Jan van Kessel II (atribuido), Mariana de Neoburgo, 1690, (Óleo sobre lienzo, 204 x 114,5 cm). Madrid, Patrimonio Nacional ( $\mathrm{n}^{\circ}$ inv. 10034432). (C) Patrimonio Nacional

ambos fueron monarcas. San Fernando fue el primer rey santo español, canonizado en 1671 por Clemente $X$, reinando ya Carlos II; y santa Elena fue la madre del primer emperador romano del cristianismo. Ambos santos son 
reconocidos por su lucha en pos de la defensa del catolicismo frente a la herejía, papel que asumieron como propio también Carlos II y Mariana de Neoburgo, y en el que estas delicadas miniaturas hacen un especial hincapié.

En estos pequeños retratos vemos cómo los soberanos ya no visten a la española y lucen pelucas infolio a la moda francesa. Desde los años setenta la moda francesa había hecho su entrada en la Corte. La llegada del sastre Joseph Capret, que realizó algunos trajes para el rey, y la posterior llegada de María Luisa de Orleans y de su guardarropa Claudio Bretón, facilitaron la difusión de los diseños franceses, los cuales se impondrán definitivamente a finales de la centuria ${ }^{34}$. De otra parte, tras la enfermedad que sufrirán Carlos II y Mariana de Neoburgo en el verano-otoño de $1696^{35}$, ambos tendrán que raparse la cabeza y empezarán a usar pelucas empolvadas a la moda francesa ${ }^{36}$. Ese nuevo gusto de la soberana por las pelucas hará que el Delfín de Francia, para ganarse su apoyo en la Corte, le enviase en 1698 "un collar de perlas que valía 25.000 doblones...; así como una peluca rubia"37. También hay constancia de que ese mismo año, el 11 de abril, el embajador francés en España, el marqués de Harcourt, enviaba una carta con la medida de la cabeza de la reina y muestras de su cabello para que se mandara desde Francia suficiente material para que su peluquero pudiera realizarle dos pelucas $^{38}$.

Luciendo la peluca infolio y dejando traslucir perfectamente la asunción de la moda francesa por parte de la reina hay otro retrato, en colección particular madrileña, que por su gran naturalismo y tremenda semejanza con las obras anteriores a la hora de recrear los detalles de la indumentaria y las joyas, puede ser también atribuido a Jan van Kessel II (Fig. 8) ${ }^{39}$. Esta efigie fue ampliamente copiada y difundida por los pintores que conformaban el obrador de la Corte, aunque con desigual fortuna ${ }^{40}$. En estos retratos podemos ver cómo la reina luce la peluca infolio, las cejas rasuradas, el collar de gruesas perlas regalo del Delfín de Francia y un traje sumamente ornamentado, rematado en el escote con multitud de capas de tul y encaje. Dado el deteriorado aspecto que presenta Mariana, estos retratos pueden fecharse

\footnotetext{
34 Margarita de Alfonso Caffarena, Las relaciones artísticas Hispano-francesas en torno a la reina María Teresa de Austria (1660-1683), tesis doctoral inédita, Universidad de Granada. Granada, 2016, p. 402.; Arianna Giorgi, España viste a la francesa. La historia de un traje de moda de la segunda mitad del siglo XVII, (Murcia: Universidad de Murcia, 2016), pp. 153-202.

${ }^{35}$ En la Biblioteca Nacional se encuentra un romance que da gracias por la recuperación de los reyes: En la dolencia, y convalecencia de nuestros inclytos monarcas... Biblioteca Nacional de España (BNE), VE/129/35. En éste se hace una referencia disimulada a la pérdida del cabello por parte de ambos: "Como colgarán las Calles/ cada uno como pueda/ y también creo, que avra/ quien cuelgue su cavellera". Martínez Leiva, "El exilio de la reina viuda...", p. 224.

36 De la enfermedad y sus consecuencias nos habla Gabriel de Maura, Vida y reinado de Carlos II, (Madrid: Espasa-Calpe, 1942), vol. III, p. 109.

37 Adalberto de Baviera, Mariana de Neoburgo, Reina de España, (Madrid: Espasa-Calpe, 1938), p. 214.

38 Alfonso Caffarena, Las relaciones artísticas, pp. 403-403 y p. 571, anexo 15; Margarita de Alfonso Caffarena, "Intercambio de objetos suntuarios y productos de lujo entre las cortes de Madrid y París en torno a las reinas María Teresa de Austria y María Luisa de Orleans", Reales Sitios, 204, (2015), pp. 6162.

39 Martínez Leiva, Mariana de Neoburgo, vol. II, pp. 120-121, cat. IM30.

40 Para las distintas copias de esta obra Martínez Leiva, Mariana de Neoburgo, vol. II, pp. 122-124, cats. IM30/1 a IM30/3.
} 


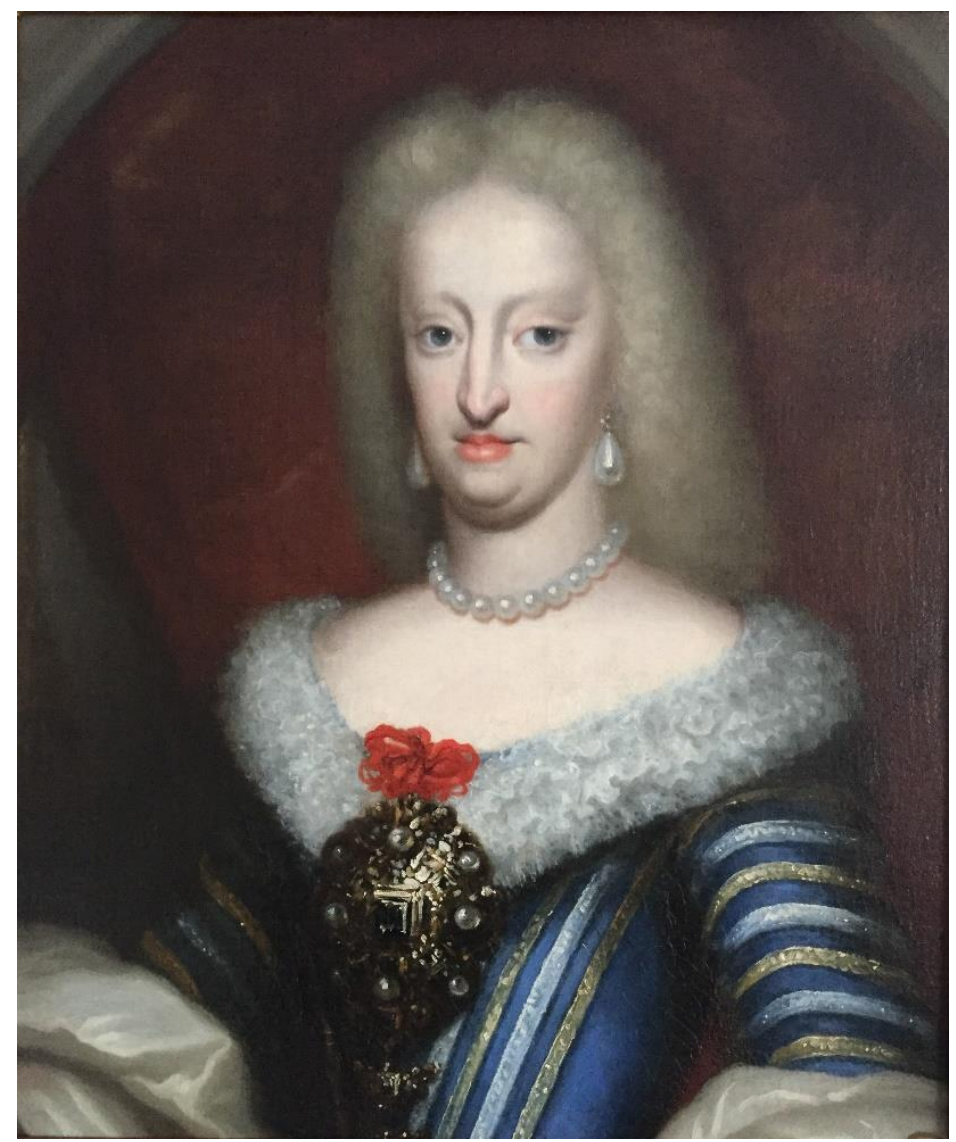

Fig. 8. Jan van Kessel II (atribuido), Mariana de Neoburgo, ca. 1698, (Óleo sobre lienzo, 68 x 55,5 cm). Madrid, Colección particular. (C) Fotografía de la autora

hacia 1698. En tan sólo ocho años, la reina pasó de ser una joven atractiva a una mujer muy avejentada debido a los agresivos tratamientos a los que los médicos la sometían para quedar embarazada, lo que hizo que en poco tiempo se debilitara su fuerte naturaleza.

\section{Un cambio en el paradigma estético, la idealización de los retratos de Jacques Courtilleau}

Ese deteriorado aspecto físico de la soberana y su deseo de no querer verse de ese modo explicaría en parte el cambio de paradigma estético, del realismo a un retrato más idealizado, y que por ello se buscase un nuevo retratista que pudiese plasmar con un lenguaje diferente, más acorde con los nuevos gustos, a la soberana ${ }^{41}$. Es así como pudo recalar en la Corte el pintor francés Jacques Courtilleau (doc. 1696-1713). De este artista desconocemos su lugar

\footnotetext{
${ }^{41}$ Durante los primeros años de Carlos II el pintor Sebastián Herrera Barnuevo también se acogerá a una fórmula más idealizada y simbólica de representar al futuro monarca, debido al aspecto enfermizo y débil de éste. Valentina Bun, "El retrato de la Corte española de la segunda mitad del siglo XVII", Temas y formas Hispánicas: Arte, cultura y sociedad, eds. Carlos Mata Induráin y Anna Morózova, (BIADIG, Biblioteca Aurea Digital del Griso, 2015), pp. 45-46.
} 


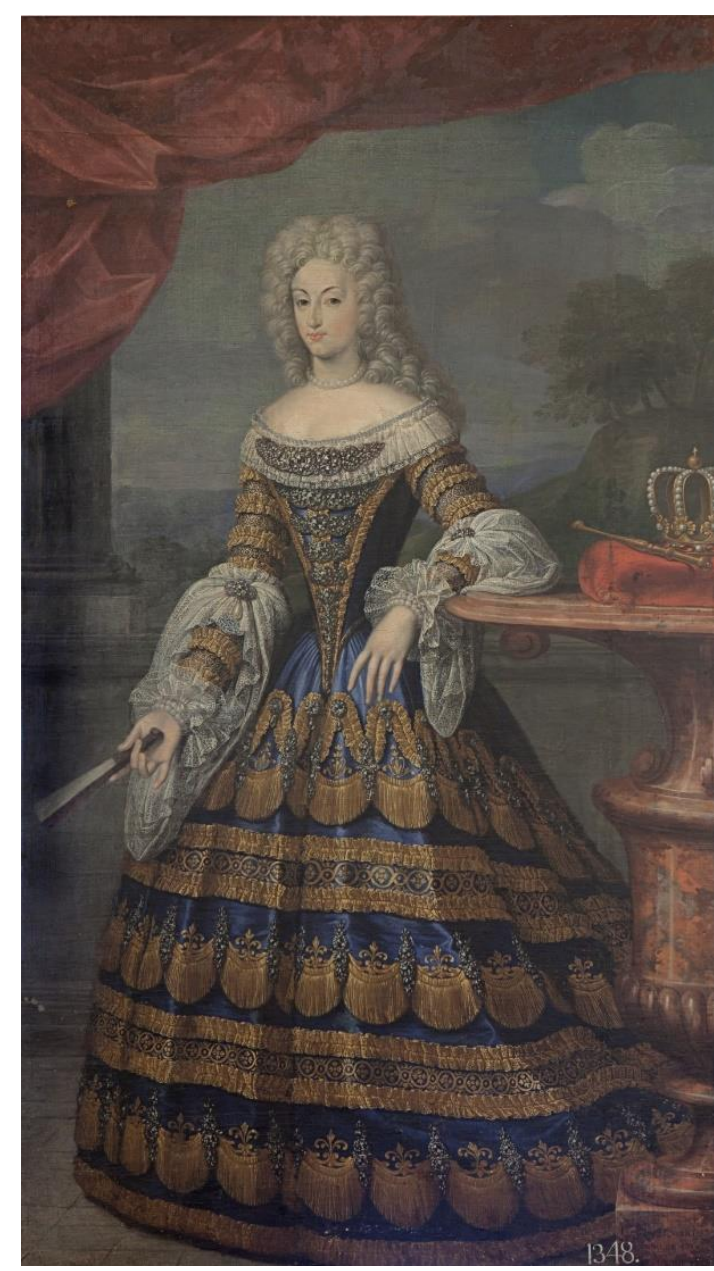

Fig. 9. Jacques Courtilleau, Mariana de Neoburgo, reina de España, 1700, (Óleo sobre lienzo, $224 \mathrm{x}$

$125 \mathrm{~cm}$ ). Palma de Mallorca, Comandancia

General de Baleares, en depósito del Museo

Nacional del Prado ( ${ }^{\circ}$ cat. P005384). (C) Museo Nacional del Prado

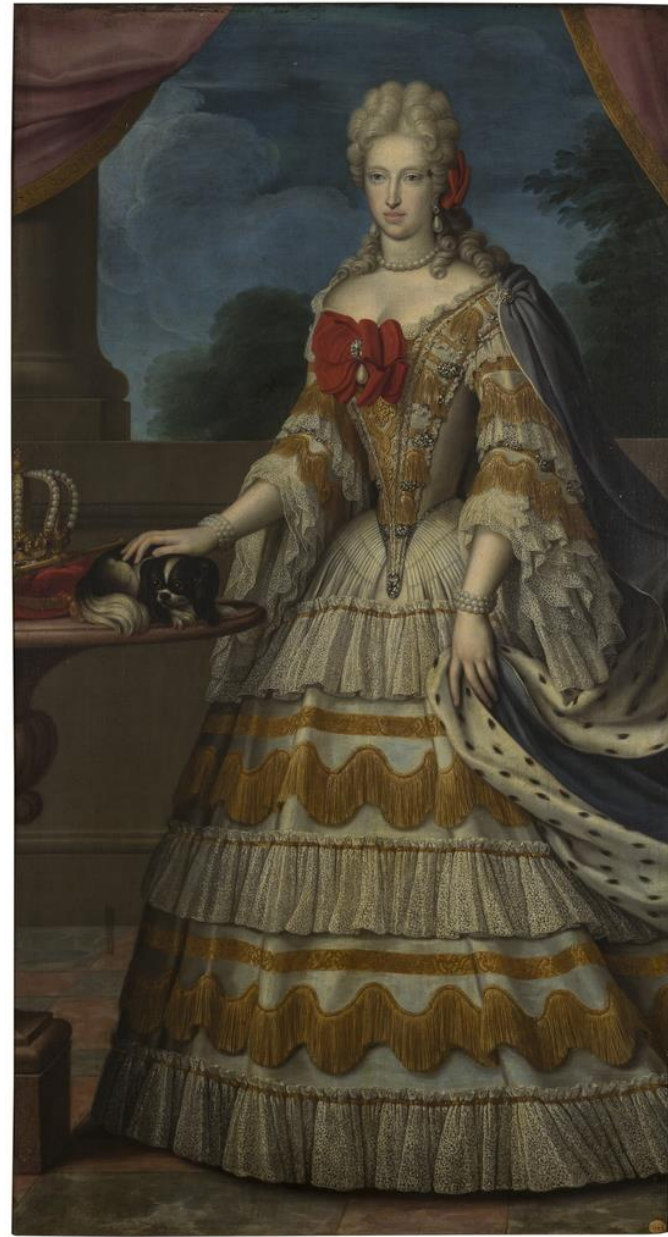

Fig. 10. Jacques Courtilleau, Mariana de Neoburgo, reina de España, ca. 1698-1700, (Óleo sobre lienzo, 206 x $110 \mathrm{~cm})$. París, Embajada de España, en depósito del Museo Nacional del Prado ( $\mathrm{n}^{\circ}$ cat. P006193). (C) Museo Nacional del Prado

de nacimiento, formación artística o cómo llegó a Madrid ${ }^{42}$. Courtilleau será pintor de cámara de la reina y desde su llegada en 1696 impondrá unos nuevos cánones artísticos. Aquí se le rebautizará como Diego del Curtillo, modo en el que aparecerá en algunos de los documentos ${ }^{43}$. De los retratos que Courtilleau realizará de la reina, y a los que posiblemente se hace referencia en el expediente personal de éste ${ }^{44}$, tan sólo se conserva uno

\footnotetext{
42 Entre los historiadores que recientemente han dedicado parte de sus investigaciones a indagar sobre la figura de Jacques Courtilleau está el profesor Ángel Aterido. A él debemos buena parte de los datos que aquí proporcionamos, ya que gentilmente nos ofreció información inédita de su tesis doctoral. Desde aquí queremos darle nuestro más profundo agradecimiento. Ángel Aterido, La pintura del último barroco en Madrid (1685-1726) de Carreño a Palomino. El final del Siglo de Oro, tesis doctoral, Universidad Complutense. (Madrid: 2011), pp. 120-122.

${ }^{43}$ Francisco Javier Sánchez Cantón, Los pintores de Cámara de los Reyes de España, (Madrid: Hausser y Menet, 1916), p. 110; Juan José Luna, "Introducción a la pintura francesa en la corte de Madrid. De Felipe III a Felipe V", en Miguel Ángel Houasse (1680-1730), (Madrid: Museo Municipal, 1981), p. 60; Aterido, La pintura del último barroco, p. 120.

44 En un documento fechado el 3 de mayo de 1700 y remitido a la reina se manifiesta que: "El rey me manda remita a V.E. el memorial adjunto de Don Diego Curtillo para que V.E., se ynforme lo que valen las pinturas que en el expresa...". Desgraciadamente no se ha localizado dicho memorial por lo que desconocemos el número de pinturas que en él se precisarían. AGP, Expedientes Personales, Ca 16810/13.
} 
fechado y firmado por el artista: "Iacobus Curtillo anno 1700". Se trata de la efigie de la soberana de cuerpo entero que pertenece al Museo del Prado (Fig. $9)^{45}$, obra que parece que formó parte de las decoraciones del Buen Retiro desde antiguo ya que figura tanto en el inventario de $1772^{46}$, como en la testamentaría de Carlos III y en el del Real Sitio de $1808^{47}$. Sin embargo, la calidad de esta obra es más bien discreta. Esto podríamos achacarlo, en parte, a los repintes, ya que debido a su mal estado de conservación pasó en 1772 por el taller del pintor Andrés de la Calleja para su compostura, pero no obstante la rigidez y frialdad de la pintura es patente ${ }^{48}$. El lienzo permite, sin embargo, ver claramente un cambio absoluto en los gustos, no sólo a la hora de la representación, sino también en la vestimenta y joyas de la reina, y una renovación del modelo con el que se realizaba el retrato oficial de la soberana. En éste aparece nuevamente con la peluca infolio y en el jubón, basquiña y mangas hay numerosos broches de diamantes que adornan el traje, el cual sigue la recargada moda francesa del momento, con presencia de abundantes puntillas, bordados y recamados de oro. Otra de las grandes novedades es la apertura total del escenario al paisaje, pero sobre todo destaca la presencia de elementos simbólicos que nos hablan de su condición de reina, como son la corona y el cetro real, que se sitúan sobre un bufete redondo, algo que rompe con la austeridad de los retratos hispánicos que habíamos estudiado anteriormente. Hasta ese momento la propia presencia regia y su indumentaria hablaba sobre el estatus del representado, a partir de ahora toda una serie de elementos iconográficos se introducirán en los lienzos: coronas, cetros, mantos de armiño, etc., para hacer hincapié en el alto rango del efigiado.

De cronología y características semejantes a este retrato se conserva otra efigie de la reina en la embajada de España en París, que pertenece al Museo del Prado (Fig. 10) ${ }^{49}$. Representa a Mariana de Neoburgo como reina de España ${ }^{50}$, y en ésta tanto el escenario, el bufete sobre el que la reina apoya su mano, el enlosado, como el tipo de corona real, toda rodeada de perlas,

\footnotetext{
45 Martínez Leiva, Mariana de Neoburgo, vol. II, pp. 137-138, cat. IM34.

46 Seguramente se trata de la obra descrita como: "1148. Otro lienzo que contiene un Retrato de la $S^{\text {ra. }}$ da. Mariana de vara y media de ancho, y dos varas de alto". AGP, Administrativa, leg. 38, exp. 45.

47 En ambos inventarios figura bajo la misma descripción: "1348. Otra de Jacobo Curtillo en el año de 1700 , con el retrato de una Reyna, de dos varas y media de alto y vara y tercia de ancho... 100rs". AGP, Administrativa, leg. 38, exp. 59; Fernando Fernández Miranda, Inventarios Reales. Carlos III (1789-1790), (Madrid: Patrimonio Nacional, 1988), vol. I, p. 353, no 3711.

48 Con esta apreciación está de acuerdo Olivier Ribeton, "Robert Gabriel Gence, vers 1670-1728 et quelques portraitistes travaillant pour la région de Bayonne dans la première moitié du XVIII ${ }^{\mathrm{e}}$ siècle. Essai de catalogue", Les Cahiers d'Histoire de l'Art, 8, (2010), p. 141, Fig. 6; y Alfonso Caffarena, Las relaciones artísticas, p. 405.

49 Éste procede de los fondos del Museo de la Trinidad y no de la colección real. En el inventario de la Trinidad se describe bajo el no 961: "Retrato de una reyna, vestida de blanco y manto azul, con un lazo encarnado en el pecho y apoyando la mano Dra sobre un perrito $q^{\mathrm{e}}$ esta en una mesa figa $\operatorname{tam}^{\circ}$ nat $^{1} \mathrm{y}$ cuerpo ento. Rectf ${ }^{\mathrm{do}}$ alto 2,06 1/2 ancho 1,10. Este cuadro tiene un sobrante de lienzo á los dos lados $\mathrm{q}^{\mathrm{e}}$ se dobla por detrás". Museo del Prado. Inventario General de Pinturas. II El Museo de la Trinidad, (Madrid: Museo del Prado, 1991), p. 296, cat. 961; Martínez Leiva, "El exilio de la reina viuda...", pp. 226-227, Fig. 11; Martínez Leiva, Mariana de Neoburgo, vol. II, pp. 130-132, cat. IM32.

50 Tanto Luna como Aterido también consideraron que se trataba de una obra de Jacques Courtilleau con anterioridad a nosotros. Luna, "Introducción a la pintura...", p. 60 y Aterido, La pintura del último barroco, p. 121, nota 313. Posteriormente la Dra. de Alfonso también ha señalado esa posibilidad. De Alfonso Caffarena, Las relaciones artísticas, p. 405. Olivier Ribeton, sin embargo, atribuye la obra a Robert Gabriel Gence y la data hacia 1711. Ribeton, "Robert Gabriel Gence...", p. 148, Figs. 21 y 22.
} 


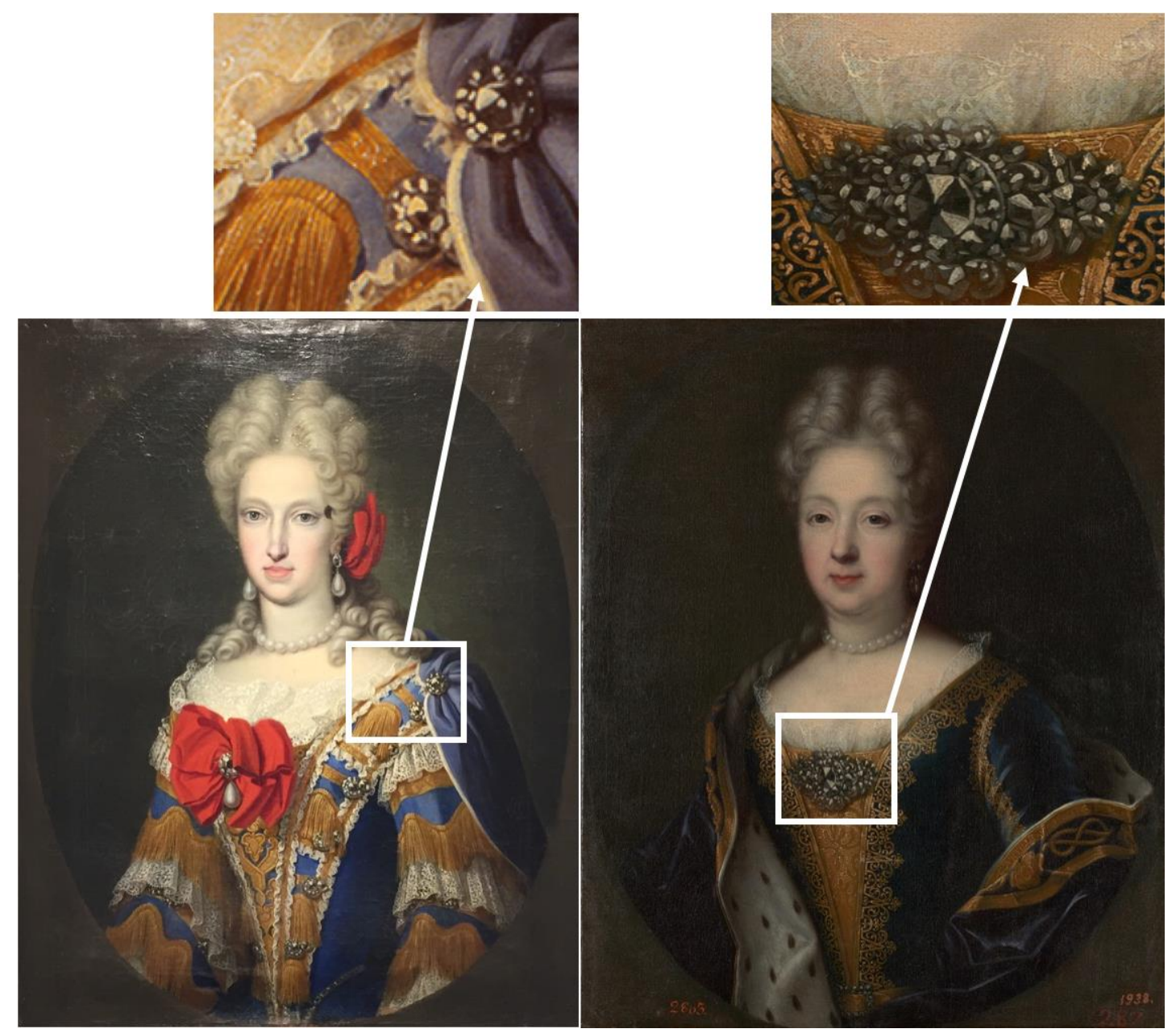

Fig. 11. Comparativa entre Jacques Coutilleau, Retrato de Mariana de Neoburgo, ca. 1700, (Óleo sobre lienzo, $83 \mathrm{x}$ $62 \mathrm{~cm}$ ). Chiusa (Italia), Museo Cívico; y el Retrato de Maria Giovanna Battista, duquesa de Saboya, 1702, (Óleo sobre lienzo, 72 x $63 \mathrm{~cm}$ ). Madrid, Museo Nacional del Prado ( ${ }^{\circ}$ cat. P002241). (C) Composición de la autora

son idénticos a los utilizados por Courtilleau en el lienzo firmado del Prado. Asimismo, lo distante del personaje, la carencia de profundidad psicológica de éste y la frialdad y rigidez de la pintura apuntarían a la autoría del pintor francés. En cuanto al aspecto de la reina, éste sigue trasluciendo el gusto por la moda gala, tanto es así que incluso al lado de su ojo izquierdo luce una mouche o lunar postizo, muy popular en la Francia del momento. Otro detalle interesante es que la soberana apoya su mano derecha sobre un pequeño perrito de pelaje blanco y negro de la raza conocida como King Charles, referencia directa a la fidelidad de ésta hacia su consorte, el rey Carlos II. En un momento en el que las diversas potencias europeas peleaban por ganarse el favor de la soberana y en el que todos sus gestos eran interpretados como apoyo o agravio hacia los intereses sucesorios de éstas, parece que Mariana 
decidió tomar partido por sí misma y su esposo e intentó dejar clara su postura a través de sus retratos ${ }^{51}$.

Siguiendo exactamente el modelo del retrato de la embajada de España, pero en busto, se encuentra en el Museo Cívico de Chiusa (Italia) otra efigie de la reina ${ }^{52}$. Ésta presenta el mismo peinado, traje, gran lazo rojo en el pecho con una perla en colgante, joyas, etc., que la de la embajada parisina. Incluso el mouche en el rostro nos habla de que ambas obras derivan de un mismo modelo común. La única diferencia entre estos retratos es que mientras el fondo de la seda del vestido en la efigie de la embajada francesa es blanco, en el de Chiusa es azul, y que el escote amplio del jubón en la obra que fue donada al Tesoro de Loreto fue tapado con una puntilla para hacer más decoroso el retrato regio dado su destino a una institución religiosa. La efigie, pese a presentar también cierta frialdad, resulta más delicada de facciones, y su colorido, gracias entre otras cosas al contraste lumínico que proporciona el fondo neutro de color oscuro, resulta muy próxima al retrato de la Duquesa de Saboya firmado por Courtilleau y fechado en 1702 del Prado $^{53}$. Esto unido a la peculiar forma de realizar las gemas por parte del artista galo, a base de prismas geométricos en diversas tonalidades de grises, que estaría presente tanto en los retratos firmados de la Duquesa de Saboya y el de Mariana del Prado como en el de la embajada de París y en el de Chiusa, permite afianzar por completo la autoría de todas estas obras a Courtilleau (Fig. 11) 54 .

Ese también sería el caso de los retratos que se conservan en el Convento de Bressanone (Italia), procedentes de Chiusa, en los que se muestra a Carlos II y Mariana de Neoburgo (Fig. 12) ${ }^{55}$. Éstos fueron enviados para conmemorar la fundación del convento de los frailes capuchinos de Chiusa por parte de la reina hacia 1700 . De hecho, en su mano derecha ésta porta los planos de construcción del edificio. En el de la soberana, tanto el rostro como el peinado son muy semejantes a los que ya mostraba en las obras de la embajada parisina y del museo Cívico que acabamos de analizar. Eso unido al hieratismo en la representación y a la nula captación psicológica de la efigiada hace que lo atribuyamos a Courtilleau en una fecha de realización próxima a 1700. De este lienzo existió otra versión, pero en el que la reina no lleva ningún plano en su mano, que fue publicado por Adalberto de Baviera y que también estuvo en el convento de Chiusa y desapareció en fecha incierta de allí ${ }^{56}$. Éste posee

\footnotetext{
${ }^{51}$ Sobre la intencionalidad política de algunas de las efigies de Mariana de Neoburgo véase Gloria Martínez Leiva, "Imagen y poder: La impronta de la reina Mariana de Neoburgo en el retrato de Corte español", en Las mujeres y las artes en la Corte española de la Edad Moderna. Seminario Internacional, coord. Beatriz Blasco Esquivias, (Madrid: Universidad Complutense de Madrid, en prensa).

52 Museo Cívico de Chiusa (Italia), óleo sobre lienzo, 83 × 62 cm. Martínez Leiva, Mariana de Neoburgo, vol. II, pp. 132-133, cat. IM32/1.

53 MNP, óleo sobre lienzo, $72 \times 63 \mathrm{~cm}$. (no cat. P002241).

54 Queremos agradecer a la Dra. Gudrun Maurer que nos enseñara en los almacenes del Museo Nacional del Prado el retrato de la Duquesa de Saboya firmado por Jacques Courtilleau y nos permitiera su análisis detallado para poder afianzar la atribución de estas obras al artista francés.

${ }_{55}$ Martínez Leiva, Mariana de Neoburgo, vol. II, pp. 139-140, cat. IM35.

56 Baviera, Mariana de Neoburgo, p. 16; Martínez Leiva, Mariana de Neoburgo, vol. II, pp. 140-141, cat. IM35/1.
} 

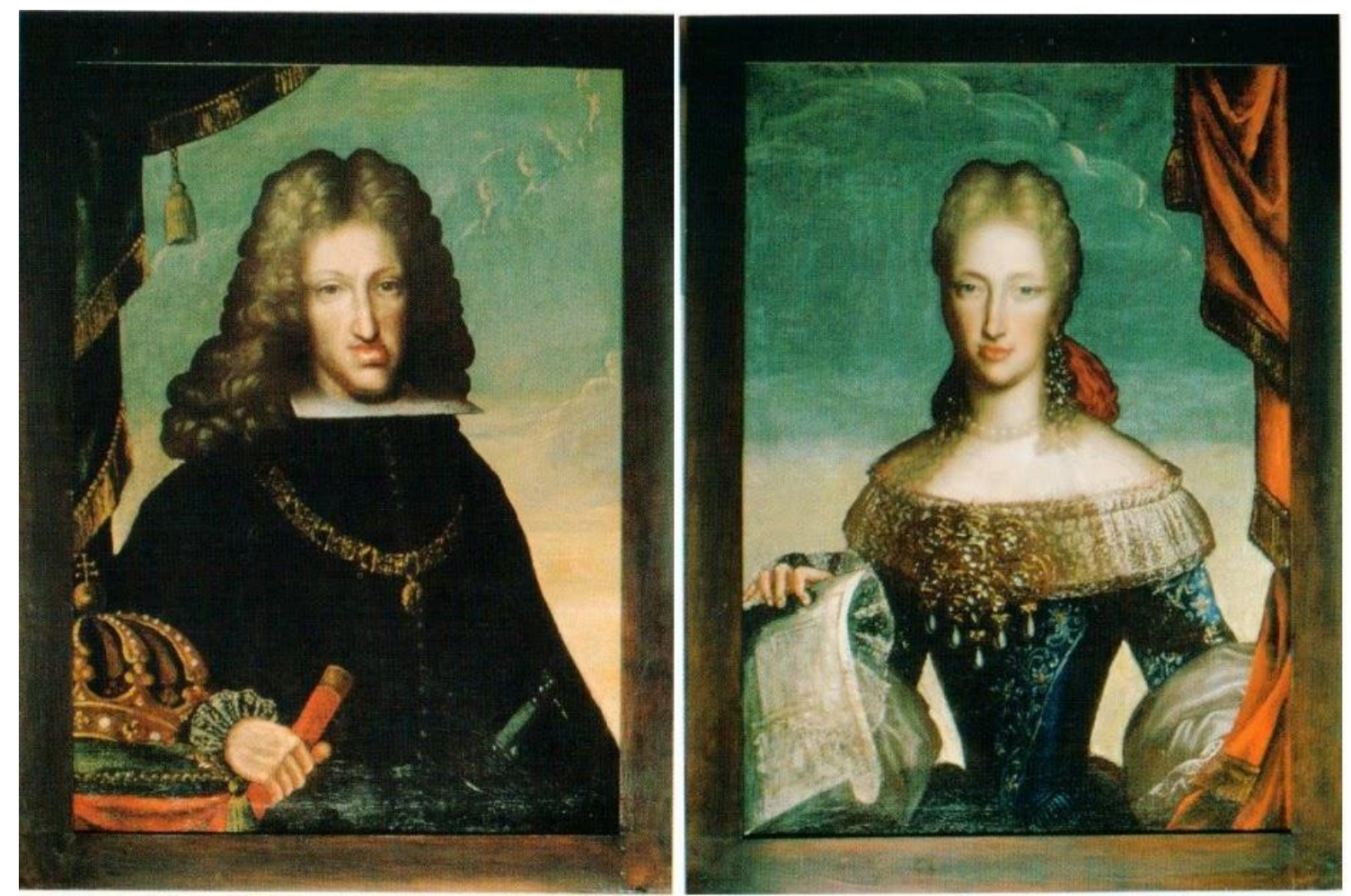

Fig. 12. Jacques Courtilleau, Carlos II y Mariana de Neoburgo, ca. 1700, (Óleo sobre lienzo, 62 x 43 cm c/u). Convento de Bressanone, Italia. (c) Convento de Bressanone

idénticas características, por lo que también consideramos que pudo haber salido de los pinceles del artista francés.

\section{Buscando una nueva iconografía: los primeros retratos de Mariana de Neoburgo como viuda}

El 1 de noviembre de 1700 fallecía en el Alcázar de Madrid Carlos II. Éste había dejado estipulado en su testamento como heredero al nieto de Luis XIV y mandaba que, hasta la llegada del duque de Anjou, futuro Felipe V, la nación debía ser gobernada por una Junta de Gobierno compuesta por la reina, el cardenal Portocarrero, el presidente de Castilla y el de Aragón, el Inquisidor General, el conde de Benavente y el conde de Aguilar, como consejero de Estado. Desde el primer momento la soberana se lleva "mal con los ministros de la Junta de Regencia y no asiste a las sesiones" ${ }^{\prime 57}$. No obstante, ella intentó reforzar su figura, como reina viuda y como gobernadora regente del reino, no sólo en el interior de la península sino también en el exterior. Para ello se servirá de sus retratos como mensaje político e intentará afianzar su figura como reina viuda ${ }^{58}$.

57 Maura, Vida y reinado, vol. III, p. 432.

58 Sobre esos intentos de hacer visible su figura como reina viuda ya trató el artículo de Carmen Sanz Ayán, "La reina viuda Mariana de Neoburgo (1700-1706). Primeras batallas contra la invisibilidad", Las 


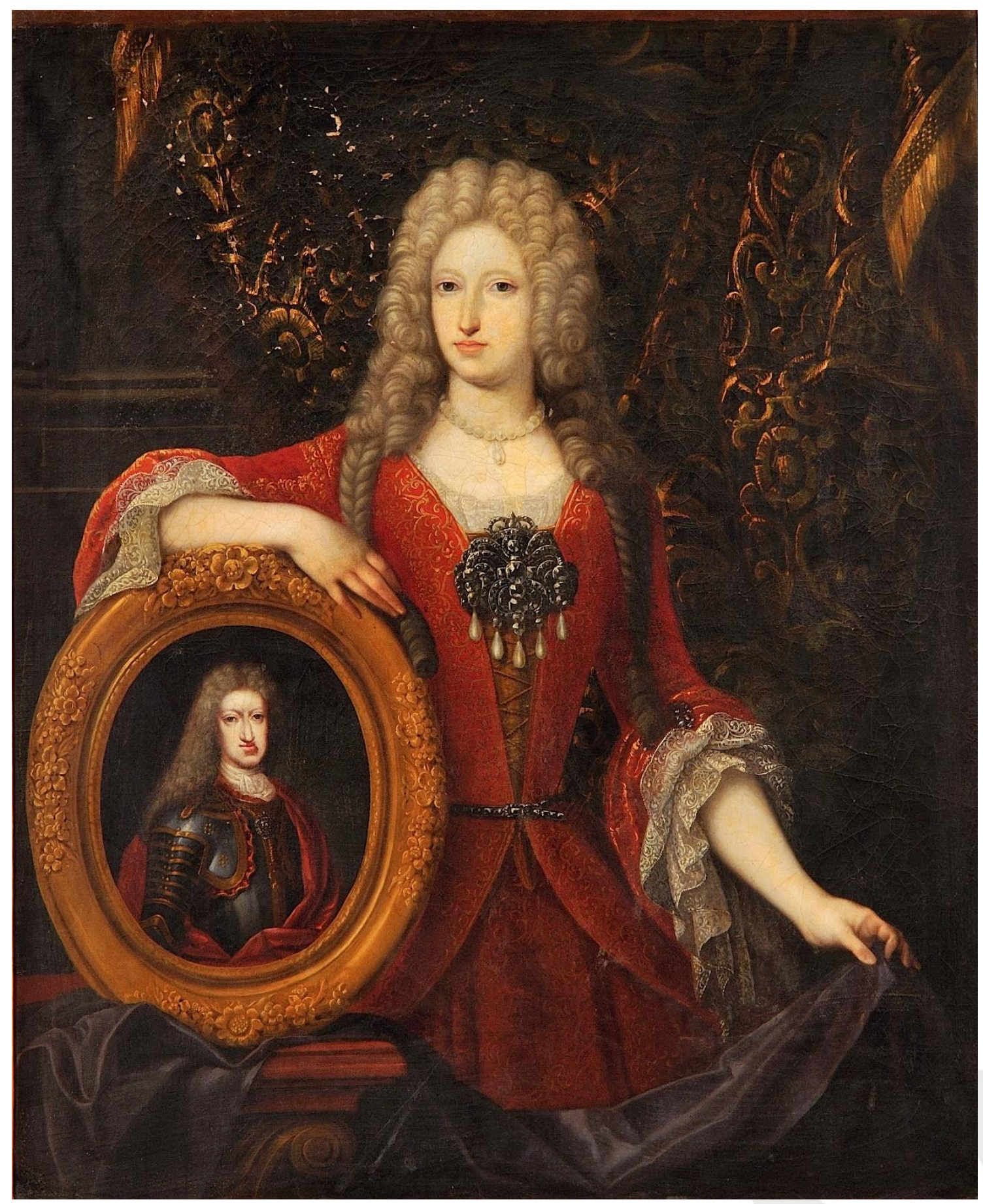

Fig. 13. Jacques Courtilleau, Mariana de Neoburgo con el retrato de su difunto esposo Carlos II, 1700-1701, (Óleo sobre lienzo, 127 x $104 \mathrm{~cm}$ ). Poggio a Caiano (Italia), Museo de la Villa Medicea di Poggio a Caiano $\left(\mathrm{n}^{\circ}\right.$ inv. 00375071). () Gallerie degli Uffizi

En este contexto es como hay que leer y entender el retrato realizado por Jacques Courtilleau de Mariana de Neoburgo portando el retrato de su difunto

relaciones discretas entre las Monarquía Hispana y Portuguesa: las Casas de las Reinas (siglos XV-XIX), coords. J. Martínez Millán y M.P. Marçal Lourenço, (Madrid: Editorial Polifemo, 2009), vol. I, pp. 459-482. 
esposo Carlos II (Fig. 13) ${ }^{59}$, en el que queda plasmado tanto el dolor por la pérdida de su esposo como su papel de reina viuda y regente. El modelo escogido por Courtilleau fue el establecido en Francia a mediados del siglo XVII tras la muerte de Luis XIII, cuando Ana de Austria se hizo con la regencia de Francia durante la minoría de Luis XIV60. En este lienzo se expresaba tanto la continuidad dinástica, como el papel de la reina de regente y el duelo por la muerte de su esposo. Esta iconografía gozará de gran éxito e impacto en la Europa de la segunda mitad del siglo XVII extendiendo su uso a otras monarquías ${ }^{61}$. Con esta elección del modelo francés se dejaban varias cosas claras. No se miró a la tradición española, Mariana no podía ni quería ser Mariana de Austria, la viuda regente ocupándose de los asuntos de Estado mientras que su hijo era menor de edad, confinada en un atuendo de monja. Ella sabía perfectamente que su papel como regente iba a ser muy corto, ya que no había dado un heredero al trono, y que sólo formaría parte de la Junta de Gobierno mientras que no hubiera llegado el futuro Felipe $V$ a España. Por tanto, tenía que postularse como viuda que todavía podía aspirar a ocupar otro trono en Europa. Es por ello que su aspecto es el de una mujer todavía joven y guapa, que no luce luto, sino que es la iconografía que la rodea la que indica que se encuentra en ese estado, con la gran cortina que le sirve de escenario realizada en terciopelo negro con decoraciones adamascadas en hilo de oro y sujetando un velo negro sobre el que se apoya el retrato en óvalo de su esposo fallecido, Carlos II. La obra expresa, sin lugar a dudas, la fidelidad de la reina hacia la memoria de su difunto marido, representándola al mismo tiempo como la continuadora de su legado. Asimismo, recurriendo al modelo francés se denotaba el definitivo cambio de gusto de la época y de la soberana; y la preeminencia del arte francés en Europa. La sobriedad de formas y lenguaje de los retratos españoles quedaba atrás, y ahora tanto el vestuario de la reina como la representación de símbolos de poder hacían gala de una nueva victoria francesa. La supremacía política de Francia en Europa se había extendido con éxito al ámbito cultural y este lienzo es una de las pruebas más patentes de ello.

Pese a la predilección que la reina parecía tener en estos momentos por Jacques Courtilleau no hay datos que apunten a que éste llegase a viajar con Mariana de Neoburgo a su exilio toledano. Sabemos que el pintor acompañó a Felipe V en su jornada de Barcelona y, el 17 de abril de 1702, desembarcaba en Nápoles formando parte del séquito del rey. En Italia, a su paso por el Piamonte retrató a María Giovanna Battista de Saboya Neumours, duquesa

\footnotetext{
${ }^{59}$ Aunque la pintura no parece conservar firma o inscripción alguna visible (no obstante, su estado de conservación es muy deficiente con lo que tampoco se puede asegurar este extremo), su estilo y técnica pictórica es la misma que podemos observar en los retratos firmados por Courtilleau que se conservan en el Museo del Prado. Esto nos ha permitido su adjudicación al pintor francés. Martínez Leiva, Mariana de Neoburgo, vol. II, pp. 143-145, cat. IM37.

60 Pierre Mignard, círculo de: Ana de Austria como viuda con el retrato de Luis XIV niño, ca. 1654. Óleo sobre lienzo, 128 × $96 \mathrm{~cm}$. Alcudia, Fundación Yannick y Ben Jakober (no inv. 605). (En web: http://2.bp.blogspot.com/-r6zLp9BTf40/VT5SOyeR0yI/AAAAAAAAAkA/UIyb1F0kA9w/s1600/inv605.JPG; consultada: 20 de octubre de 2019).

${ }^{61}$ Sobre este asunto véase Emmanuel Coquery, "Le portrait en tableau", en Visages du gran Siècle. Le portrait français sous le règne de Louis XIV, 1660-1715 (Musée de Beaux-Arts de Nantes y Musée des Augustins de Toulouse, 1997), pp. 121-136.
} 

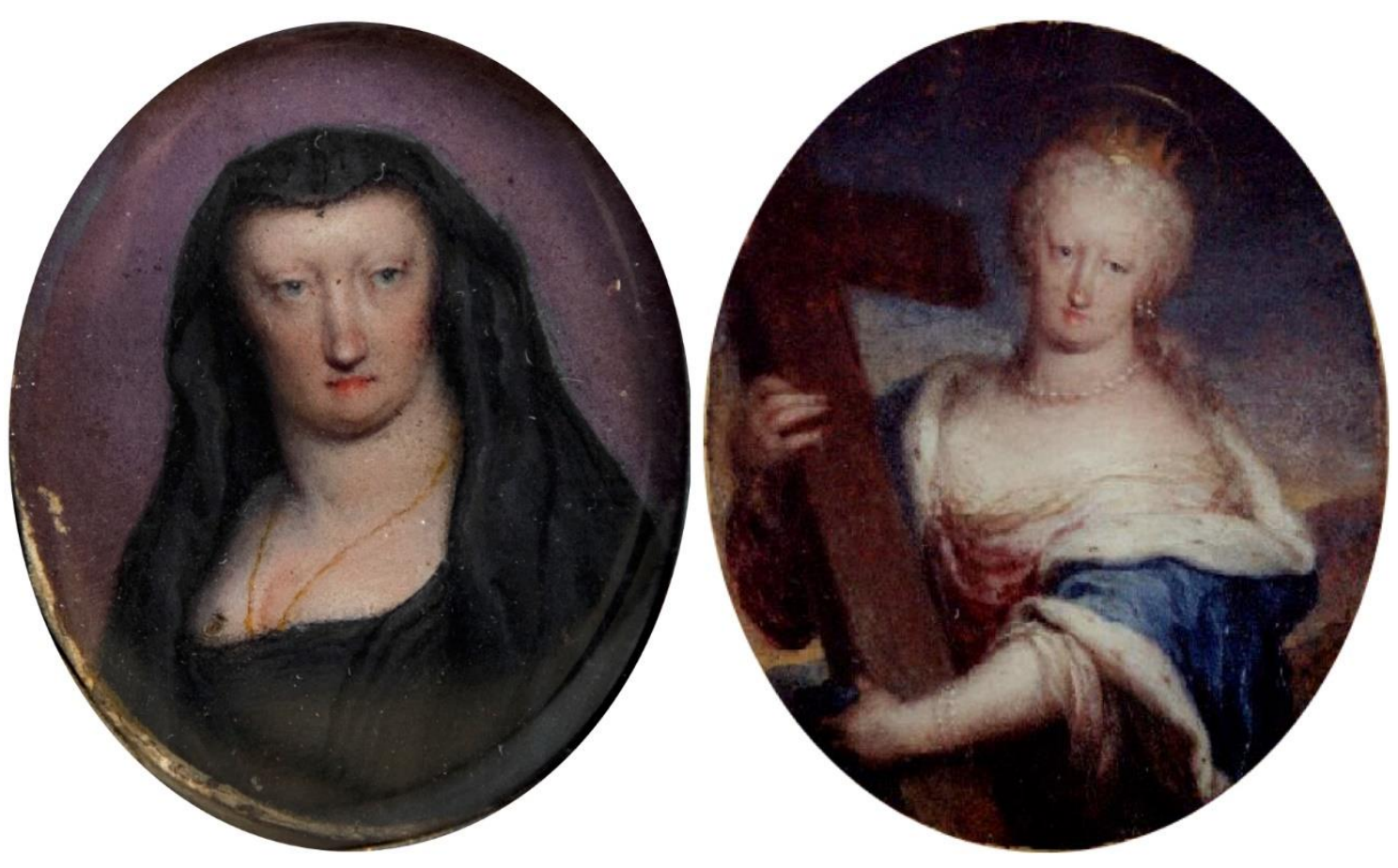

Fig. 14. Jan van Kessel II, Comparativa entre las miniaturas del retrato de Mariana de Neoburgo, ca. 1701-1706, (Óleo sobre naipe, 32 × $27 \mathrm{~mm}$ ). Madrid, Museo Nacional de Artes Decorativas ( $\mathrm{n}^{\circ}$ inv. CE27316). () Museo Nacional de Artes Decorativas; y el retrato a lo divino de Mariana de Neoburgo como santa Elena, ca. 1698, (Óleo sobre cobre, 79 x $65 \mathrm{~mm}$ ). Madrid, Colección particular

de Saboya y princesa de Piamonte, obra a la que anteriormente ya nos hemos referido (Fig. 11). Al no acompañar Courtilleau a la reina a Toledo suponemos que el retrato de ésta como viuda fue realizado en los dos meses y medio previos a la salida de la soberana del Alcázar de Madrid. El destino de esta obra fue, posiblemente, el elector Juan Guillermo, hermano de Mariana, para anunciar así a éste, de una manera gráfica, su nuevo estado. Tras la muerte de Juan Guillermo la obra sería heredada por Ana María Luisa de Médici, viuda de éste, y llevada consigo al Palazzo Pitti de Florencia, lugar donde permaneció hasta el siglo XIX62.

Quien sí viajó con Mariana de Neoburgo a Toledo fue Jan van Kessel II, que el 26 de enero de 1701 juraba un nuevo cargo como mozo del oficio de la Furriera de la Casa de la reina viuda Mariana de Neoburgo y dos días más tarde era ascendido a ayuda de este oficio ${ }^{63}$. En Toledo sabemos que el artista flamenco realizó muchos retratos de la soberana para dejar constancia de su nueva imagen como reina viuda ${ }^{64}$. Hasta ahora no se conocía ninguna de esas

62 La obra en la actualidad se encuentra en la Villa Medicea di Poggio a Caiano adonde llegó en 1816 procedente del Palazzo Pitti de Florencia, describiéndose como: "dipintovi fino al ginocchio Principessa vestita di broccato rosso con capelli bianchi tenente nella destra medaglione e espressovi Principe". Inventario dei Mobili di Poggio a Caiano", 31 de diciembre de 1816. Archivio di Stato, Florencia (AS), I. E R. Corte, n. 3930.

63 Aterido, El final del Siglo de Oro, vol. II, p. 168.

64 "Pero habiendo muerto la Reina nuestra señora, Doña María Luisa, no se atrasó por eso la fortuna de Vanchesel: pues continuó en la gracia de la Serenísima Reina Doña María Ana de Neoburg, a quien retrató diferentes veces, como también al Señor Carlos Segundo; después de cuya muerte se fue en asistencia 
obras, pero aquí queremos atribuir una a este periodo del pintor. En el Museo de Artes Decorativas de Madrid se conserva una pequeña miniatura engastada en un rico joyel de plata y esmeraldas en la que se muestra el retrato directo y simple en busto de la soberana vestida de luto. Hasta ahora el planteamiento que se había seguido a la hora de analizar esta obra era que ésta seguía el modelo establecido por Courtilleau en las efigies de la reina realizadas por éste en Bayona. En concreto se veía como continuación de la estela del retrato conservado en el Château de Haïtze (Fig. 15) ${ }^{65}$. Es por ello que la miniatura se fechaba entre 1710 y $1713^{66}$. Sin embargo, si comparamos ésta con la de la reina como santa Elena67 (Fig. 14) y con la de Carlos II con armadura ${ }^{68}$, ambas consideradas originales de Jan van Kessel II, veremos que los puntos en común entre estas obras son muchos. Así, el rostro de la reina tanto en la miniatura a lo divino como en la que nos ocupa tiene forma de triángulo invertido. En ambas los ojos de la soberana son pequeños y están marcados en sus extremos los huesos frontales y occipitales. La nariz, recta y larga divide el rostro en dos de forma simétrica, terminando en una pequeña boca de color carmín nacarado. El cuello y escote en ambos retratos es robusto y amplio, con fuerte sombra marcada debajo de la barbilla para hacer la división entre el rostro y el cuello. El parecido en la realización de los diversos elementos fisionómicos es tal que el planteamiento de que nos encontremos ante obras del mismo artífice es más que plausible. Asimismo, al cotejar el color del fondo del retrato de la reina como viuda, vemos que está dentro de la paleta utilizada por Van Kessel y que ya en la miniatura de Carlos II con armadura del Museo de Artes Decorativas el artista utilizó esos mismos tonos violáceos a la hora de recrear el escenario. Por último, sabemos que durante el tiempo que Van Kessel estuvo en Toledo realizó retratos en miniatura para la soberana. Durante el encuentro de Mariana con los reyes Felipe V y María Luisa Gabriela de Saboya en el verano de 1703 en Aranjuez la reina obsequió con su retrato rodeado de brillantes a la princesa de los Ursinos ${ }^{69}$. Éste tuvo que ser realizado por Van Kessel, ya que era el único pintor en nómina de la soberana en ese momento. La miniatura debió ser para la reina viuda una forma económica y más conveniente, por su pequeño tamaño, con la que poder agasajar a sus visitas o enviar como presente y difundir así su imagen como viuda doliente y soberana, demostrando de este modo la importancia del retrato como vehi-

de la Reina viuda a Toledo, donde hizo muchos retratos; y después de haberse pasado a Bayona de Francia esta señora, se vino Vanchesel a Madrid...", Palomino, El Museo pictórico, p. 1122.

65 Martínez Leiva, Mariana de Neoburgo, vol. II, pp. 150-152, cat. IM40.

66 MNAD, óleo sobre naipe, $32 \times 27 \mathrm{~mm}$. ( $\mathrm{n}^{\circ}$ inv. CE27316). Quien esto escribe y otros autores así lo habíamos planteado, véanse: Ángel Aterido, "La herencia de Mariana de Neoburgo", en Inventarios Reales. Colecciones de pinturas de Felipe V e Isabel Farnesio, Ángel Aterido, Juan Martínez Cuesta y José Juan Pérez Preciado, (Madrid: Fundación de Apoyo a la Historia del Arte Hispánico, 2004), vol. I, p. 194; Martínez Leiva, "El exilio de la reina viuda...", p. 233, Fig. 13; Mercedes Simal, "Óleo sobre naipe. Dos pequeños retratos de Carlos II (según Van Kessel II) y Mariana de Neoburgo del Museo Nacional de Artes Decorativas", Además de. Revista online de artes decorativas y diseño, 3, (2017), pp. 45-47, Fig. 12.

67 Anteriormente en Galería Caylus, Madrid.

68 MNAD, óleo sobre naipe, $41 \times 35 \mathrm{~mm}$. ( $\mathrm{n}^{\circ}$ inv. CE26627).

69 Baviera, Mariana de Neoburgo, p. 323. 


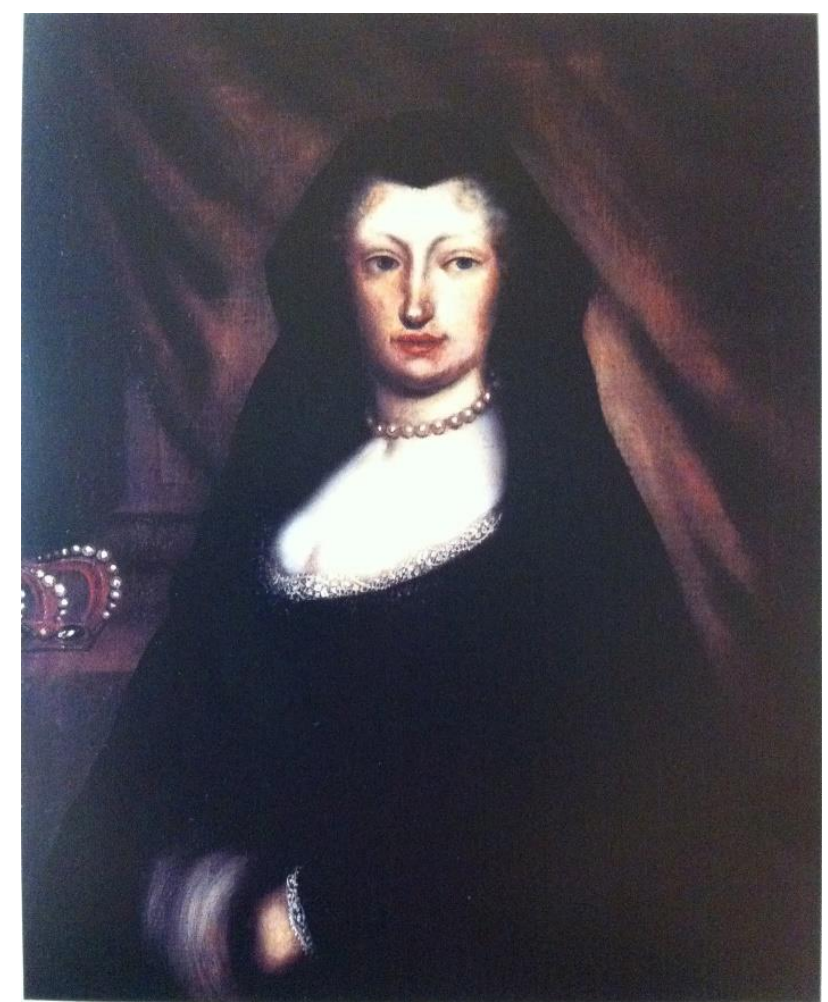

Fig. 15. Jacques Courtilleau, Mariana de Neoburgo como reina viuda, ca. 1710-1713, (Óleo sobre lienzo, 77,5 x $61 \mathrm{~cm}$ ). Ustaritz (Francia), Château de Haïtze. (C) Château de Haïtze

culo político y como forma de relacionarse entre las cortes ${ }^{70}$.

Así pues, a la vista de este nuevo análisis, hay que considerar a Jan van Kessel II como el responsable de gestar la iconografía de la reina como viuda. Una iconografía directa y sencilla, con la soberana de ligero perfil y vestida con largo velo negro cubriendo su cabeza y hombros y un jubón también negro, pero de amplio escote. Un modelo simple, y cuyo ascetismo de formas y colorido entroncaba todavía con la tradición hispánica. Tras el destierro de la soberana a Francia el artista flamenco regresará a la Villa y Corte y todavía "logró la ocasión de retratar al Rey nuestro señor Don Felipe Quinto, aunque no con tanto acierto, como se esperaba"71. En 1711 fallecía en Madrid sin otorgar testamento ${ }^{72}$.

Por su parte la reina viuda, en 1706, tras cinco años viviendo en el Alcázar toledano ${ }^{73}$, abandonó la península ibérica tras mostrar públicamente su apoyo al archiduque Carlos de Austria en su empeño de suceder a Carlos II al frente de la Corona de España ${ }^{74}$. Su destino fue el destierro en Bayona. Como hemos

\footnotetext{
${ }^{70}$ Sobre el importante papel de las miniaturas hay interesantes reflexiones en la tesis doctoral de Julia de la Torre Fazio, El Retrato en miniatura español bajo los reinados de Felipe II y Felipe III, tesis doctoral inédita, Universidad de Málaga. (Málaga: 2009), pp. 55-93.

71 Palomino, El Museo pictórico, p. 1122.

72 Aterido, El final del Siglo de Oro, vol. II, p. 168.

73 Sobre la estancia de Mariana en Toledo véanse África García Fernández, Entre Austrias y Borbones: destierro de $D^{a}$ María Ana de Neoburgo, (Toledo, 1994); Sanz Ayán, "La reina viuda..."; Ángel Santos Vaquero, "Mariana de Neoburgo en Toledo", Cuadernos de Historia Moderna, 36, (2011), pp. 151-175; Martínez Leiva, Mariana de Neoburgo, vol. I, pp. 217-230, cap. 2.2.

74 El 26 de abril de 1706 incluso publicó un bando llamando a los caballeros de las Órdenes Militares a luchar a favor del archiduque. BNE, Mss. 10330.
} 
dicho, Jan van Kessel II no la acompañará en su viaje a Francia, por lo que la reina quedará sin un pintor que la asista. Esto será así hasta que, el 20 de junio de 1710, Jacques Courtilleau vuelva al servicio de la reina viuda y se le asigne una compensación de 40 sueldos de ración diaria ${ }^{75}$. Aunque la intención de Courtilleau había sido la de hacerse un hueco entre los pintores al servicio del rey Felipe V, está claro que no consiguió su objetivo.

El único retrato que conservamos de esta nueva etapa del artista francés como pintor de la reina, entre su llegada en 1710 y su fallecimiento en 1713, es en el que sigue la estela marcada por Van Kessel para representar oficialmente a la soberana como viuda (Fig. 14). El retrato de aparato simbólico que había realizado de Mariana nada más morir Carlos II (Fig. 13) era demasiado ostentoso. El modelo iconográfico más simple pero efectista concebido por Van Kessel permitía, sin ser teatral, recordar, a quien lo viera o recibiera, su papel de reina viuda. En el retrato de Mariana de Neoburgo como viuda del Château de Haïtze (Fig. 15) ésta se muestra como una mujer todavía joven y atractiva. Aparece de tres cuartos, vestida de negro y con un largo velo, también negro, que cubre toda su figura ${ }^{76}$. Como único adorno lleva el collar de perlas que ya le vimos lucir en sus años finales en España y como atributo de su dignidad una corona, rodeada de perlas, que descansa sobre un bufete, igual a la que podemos observar en el retrato de Courtilleau firmado del Prado (Fig. 9). La simplicidad de elementos y el cromatismo del lienzo chocan con la ampulosidad y colorido más intenso de los anteriores realizados por el pintor francés, lo que también indicaría que muy probablemente se circunscribió a seguir un modelo ya establecido. El éxito de la composición estribó seguramente en que, pese a su aparente sencillez, esta iconografía transmitía un mensaje directo y potente: sigo siendo reina viuda de España.

Jan van Kessel II y Jacques Courtilleau representan pues dos formas de entender la pintura contrapuestas que, a pesar de ello, convivieron durante un tiempo y que incluso llegaron a retroalimentarse. Ambos consiguieron mostrar la imagen y estatus de Mariana de Neoburgo como reina, uno según el realismo que había imperado en España y el otro representando a la perfección la idealización y los nuevos aires franceses que en el siglo XVIII dominarán Europa.

\footnotetext{
75 Aterido, La pintura del último barroco, p. 122; Aterido, El final del Siglo de Oro, vol. II, p. 83.

76 Este retrato fue regalado por la reina a su dama de honor, Catherine Josèphe d'Urtubie, esposa en segundas nupcias del conde de Bruix, primer mayordomo de la reina viuda. Jean-Georges Lavit, "MarieAnne de Neubourg, reine douairière d'Espagne", en Du Duc D'Anjou à Philippe $V$, le premier Bourbon d'Espagne, (Paris: Musée de L'Île de France, 1993), pp. 34-35; Ribeton, "Robert Gabriel Gence...", pp. 147-148, Fig. 18; Martínez Leiva, "El exilio de la reina viuda...", pp. 232-233, Fig. 12; Martínez Leiva, Mariana de Neoburgo, vol. II, pp. 150-152, cat. IM40.
} 
Bibliografía:

Alfonso Caffarena 2015: Margarita de Alfonso Caffarena "Intercambio de objetos suntuarios y productos de lujo entre las cortes de Madrid y París en torno a las reinas María Teresa de Austria y María Luisa de Orleans", Reales Sitios, 204, (2015), pp. 38-65.

Alfonso Caffarena 2016: Margarita de Alfonso Caffarena, Las relaciones artísticas Hispano-francesas en torno a la reina María Teresa de Austria (1660-1683), Tesis doctoral inédita, Universidad de Granada. (Granada: 2016).

Aterido 2004: Ángel Aterido, "La herencia de Mariana de Neoburgo", en Ángel Aterido, Juan Martínez Cuesta y José Juan Pérez Preciado, Inventarios Reales. Colecciones de Pinturas de Felipe $V$ e Isabel de Farnesio, (Madrid: Fundación de Apoyo a la Historia del Arte Hispánico, 2004), vol. I, pp. 192-205.

Aterido 2011: Ángel Aterido, La pintura del último barroco en Madrid (16851726) de Carreño a Palomino. El final del Siglo de Oro, Tesis doctoral inédita, Universidad Complutense de Madrid. (Madrid: 2011).

Aterido 2015: Ángel Aterido, El final del Siglo de Oro. La Pintura en Madrid en el cambio dinástico 1685-1726, (Madrid: CSIC, 2015).

Barbeito 1992: José Manuel Barbeito, El Alcázar de Madrid, (Madrid: Colegio Oficial de Arquitectos de Madrid, 1992).

Baviera 1938: Adalberto Baviera, Mariana de Neoburgo, Reina de España, (Madrid: Espasa-Calpe, 1938).

Bun 2015: Valentina Bun "El retrato de la Corte española de la segunda mitad del siglo XVII", Temas y formas Hispánicas: Arte, cultura y sociedad, eds. Carlos Mata Induráin y Anna Morózova, (BIADIG, Biblioteca Áurea Digital del Griso, 2015), pp. 43-51. (En web:

http://dadun.unav.edu/handle/10171/37969, consultada: 15 de septiembre de 2019).

Coquery 1997: Emmanuel Coquery, "Le portrait en tableau", en Visages du gran Siècle. Le portrait français sous le règne de Louis XIV, 1660-1715, (Musée de Beaux-Arts de Nantes y Musée des Augustins de Toulouse, 1997), pp. 121-136.

Díaz Padrón 2008: Matías Díaz Padrón, "Van Dyck: La influencia del retrato del más prestigioso discípulo de Rubens en la pintura española del siglo XVII", Anuario de Estudios Atlánticos, 54-II, (2008), pp. 229-263. (En web:

https://www.redalyc.org/pdf/2744/274420615008.pdf, consultada: 20 de octubre de 2019). 
Díaz Padrón 2011: Matías Díaz Padrón, "Prestigio y fortuna crítica de Van Dyck en los tratadistas españoles", Archivo Español de Arte, 333, (2011), pp. 41-58. (En web:

http://archivoespañoldearte. revistas.csic.es/index.php/aea/article/view/455 /451, consultada: 20 de octubre de 2019).

Fernández Bayton 1985: Gloria Fernández Bayton, Inventarios Reales. Testamentaría de Carlos II, vol. III, (Madrid: Museo del Prado, 1985).

Fernández Miranda 1988: Fernando Fernández Miranda, Inventarios Reales. Carlos III (1789-1790), (Madrid: Patrimonio Nacional, 1988).

García Fernández 1994: África García Fernández, Entre Austrias y Borbones: destierro de Da María Ana de Neoburgo, (Toledo, 1994).

García-Frías 2001: Carmen García-Frías, "Dos dibujos inéditos de los Aposentos Reales de San Lorenzo de 1755", en Reales Sitios, 150, (2001), pp. 16-25.

García-Frías 2001: Carmen García-Frías, "La retratística de la Casa de Austria en el Monasterio del Escorial", en El Monasterio del Escorial y la pintura. Actas del Simposium, coord. Francisco Javier Campos y Fernández de Sevilla, (San Lorenzo de El Escorial: Real Centro Universitario Escorial-María Cristina, 2001), pp. 395-419.

Giorgi 2016: Arianna Giorgi, España viste a la francesa. La historia de un traje de moda de la segunda mitad del siglo XVII, (Murcia: Universidad de Murcia, 2016).

Laguna Enrique 2013: Martha Elizabeth Laguna Enrique, El Museo Nacional de Bellas Artes de la Habana y la colección de retratos de pintura española del siglo XIX, (Salamanca: Universidad de Salamanca, 2013).

Lavit 1993: Jean-Georges Lavit, "Marie-Anne de Neubourg, reine douairière d'Espagne", en Du Duc D'Anjou à Philippe V, le premier Bourbon d'Espagne, (Paris: Musée de L'Île de France, 1993), pp. 34-35.

Luna 1981: Juan José Luna, "Introducción a la pintura francesa en la corte de Madrid. De Felipe III a Felipe V", en Miguel Ángel Houasse (1680-1730), (Madrid: Museo Municipal, 1981), pp. 43-64.

Madrid 2014: Madrid: El retrato en las colecciones reales de Patrimonio Nacional. De Juan de Flandes a Antonio López, (Madrid: Patrimonio Nacional, 2014).

Martínez Leiva 2013: Gloria Martínez Leiva, "El exilio de la reina viuda Mariana de Neoburgo y la configuración de un nuevo retrato áulico", en Carlos II y el Arte de su Tiempo, coord. Alfonso Rodríguez G. de Ceballos y Ángel Rodríguez Rebollo, (Madrid: Fundación Universitaria Española, 2013), pp. 219-256. (En web:

https://www.academia.edu/12900071/El_exilio_de_la_reina_viuda_Mariana _de_Neoburgo_y_la_configuraci\%C3\%B3n_de_un_nuevo_retrato_\%C3\%A1 ulico, consultada: 20 de octubre de 2019). 
Martínez Leiva 2019: Gloria Martínez Leiva, Mariana de Neoburgo (16671740). Escenarios, imagen y posesiones de una reina, Tesis doctoral inédita. Universidad Complutense de Madrid. (Madrid: 2019).

Martínez Leiva 2019: Gloria Martínez Leiva, "Imagen y poder: La impronta de la reina Mariana de Neoburgo en el retrato de Corte español", en Las mujeres y las artes en la Corte española de la Edad Moderna. Seminario Internacional, coord. Beatriz Blasco Esquivias, (Madrid: Universidad Complutense de Madrid, en prensa).

Maura Gamazo 1942: Gabriel de Maura Gamazo, Vida y reinado de Carlos II, 3 vols., (Madrid: Espasa-Calpe, 1942).

Museo del Prado 1991: Museo del Prado. Inventario General de Pinturas. II El Museo de la Trinidad, (Madrid: Museo del Prado, 1991).

Museo del Prado 1996: Museo del Prado. Inventario General de Pinturas. III Nuevas Adquisiciones, Museo Iconográfico y Tapices, (Madrid: Museo del Prado, 1996).

Palomino de Castro 1947: Antonio Palomino de Castro, El Museo pictórico y escala óptica. II. Práctica de la Pintura y III. El Parnaso español pintoresco y laureado, (Madrid: Ed. Aguilar, 1947).

Pascual Chenel 2010: Álvaro Pascual Chenel, El retrato de Estado durante el reinado de Carlos II. Imagen y propaganda, (Madrid: Fundación Universitaria Española, 2010).

Ribeton 2010: Olivier Ribeton, "Robert Gabriel Gence, vers 1670-1728 et quelques portraitistes travaillant pour la région de Bayonne dans la première moitié du XVIII ${ }^{\mathrm{e}}$ siècle. Essai de catalogue", Les Cahiers d'Histoire de l'Art, 8, (2010), pp. 138-156.

Rodríguez Rebollo 2013: Ángel Rodríguez Rebollo, "A propósito de Luca Giordano: Los Reales Sitios durante el reinado de Carlos II. Una aproximación a través de los inventarios", en Carlos II y el Arte de su Tiempo, coord. Alfonso Rodríguez G. de Ceballos y Ángel Rodríguez Rebollo, (Madrid: Fundación Universitaria Española, 2013), pp. 107-155.

Sánchez Cantón 1916: Francisco Javier Sánchez Cantón, Los pintores de Cámara de los Reyes de España, (Madrid: Hausser y Menet, 1916).

Sánchez del Peral 2001: Juan Ramón Sánchez del Peral, "Jan van Kessel II y la Joya Grande de Mariana de Neoburgo: consideraciones sobre el retrato portátil en la época de Carlos II", Reales Sitios, 150, (2001), pp. 65-74.

Sancho y Martínez Leiva 2003: José Luis Sancho y Gloria Martínez Leiva, "¿Dónde está el rey? El ritmo estacional de la corte española y la decoración de los Reales Sitios (1650-1700)", en Cortes del Barroco, de Bernini y Velázquez a Luca Giordano, (Madrid: Patrimonio Nacional, 2003), pp. 85-98. (En web: 
https://www.academia.edu/12883285/_D\%C3\%B3nde_est\%C3\%A1_el_Re Y_El_ritmo_estacional_de_la_corte_espa\%C3\%B10la_y_la_decoraci\%C3\%B 3n_de_los_Sitios_Reales_1650-1700_, consultada: 20 de octubre de 2019).

Santos Vaquero 2011: Ángel Santos Vaquero, "Mariana de Neoburgo en Toledo", Cuadernos de Historia Moderna, 36, (2011), pp. 151-175. (En web: https://revistas.ucm.es/index.php/CHMO/article/view/37361/36161, consultada: 20 de octubre de 2019),

Sanz Ayán 2009: Carmen Sanz Ayán, "La reina viuda Mariana de Neoburgo (1700-1706). Primeras batallas contra la invisibilidad", Las relaciones discretas entre las Monarquía Hispana y Portuguesa: las Casas de las Reinas (siglos XV-XIX), coord. J. Martínez Millán y M.P. Marçal Lourenço, (Madrid: Editorial Polifemo, 2009), vol. I, pp. 459-482.

Simal 2017: Mercedes Simal, "Óleo sobre naipe. Dos pequeños retratos de Carlos II (según Van Kessel II) y Mariana de Neoburgo del Museo Nacional de Artes Decorativas", Además de. Revista online de artes decorativas y diseño, 3, (2017), pp. 29-52. (En web:

https://www.academia.edu/33740149/_\%C3\%93leo_sobre_naipe._Dos_pe que\%C3\%B1os_retratos_de_Carlos_II_Y_Mariana_de_Neoburgo_obra_de_J an_Van_Kessel_II_y_Jacques_Courtilleau_en_el_Museo_Nacional_de_Artes _Decorativas_Adem\%C3\%A1s_de._Revista_online_de_artes_decorativas_y _dise\%C3\%B10_n\%C3\%BAm._3_2017_pp._29-55, consultada: 20 de octubre de 2019).

Sullivan 1989: Edward J. Sullivan, Claudio Coello y la pintura barroca madrileña, (Madrid: Nerea, 1989).

Torre Fazio 2009: Julia de la torre Fazio, El Retrato en miniatura español bajo los reinados de Felipe II y Felipe III, Tesis doctoral inédita, Universidad de Málaga. (Málaga: 2009).

Valdivieso González 1983: Enrique Valdivieso González, "Un nuevo retrato de familia de Jan Van Kessel, el Joven", Boletín del Seminario de Estudios de Arte y Arqueología, 49, (1983), pp. 492-493. (En web:

https://dialnet.unirioja.es/servlet/articulo?codigo $=1960268$, consultada: 20 de octubre de 2019).

Zapata 2000: María Teresa Zapata, La entrada en la Corte de María Luisa de Orleans. Arte y fiesta en el Madrid de Carlos II, (Madrid: Fundación de Apoyo a la Historia del Arte Hispánico, 2000).

Enviado: 24/09/2019

Aceptado: 22/10/2019 